\title{
Epigenetic regulation by histone demethylases in hypoxia
}

The response to hypoxia is primarily mediated by the hypoxia-inducible transcription factor (HIF). Levels of HIF are regulated by the oxygen-sensing HIF hydroxylases, members of the 2-oxoglutarate (2OG) dependent oxygenase family. JmjC-domain containing histone lysine demethylases (JmjC-KDMs), also members of the $20 \mathrm{G}$ oxygenase family, are key epigenetic regulators that modulate the methylation levels of histone tails. Kinetic studies of the JmjC-KDMs indicate they could also act in an oxygen-sensitive manner. This may have important implications for epigenetic regulation in hypoxia. In this review we examine evidence that the levels and activity of JmjC-KDMs are sensitive to oxygen availability, and consider how this may influence their roles in early development and hypoxic disease states including cancer and cardiovascular disease.

Keywords: 2-oxoglutarate dependent oxygenases $\bullet$ cancer $\bullet$ cardiovascular diseases - development $\bullet$ epigenetic regulation $\bullet \mathrm{H} 3 \bullet \mathrm{HIF} \bullet$ histone $3 \bullet$ histone demethylases

- hypoxia $\bullet$ KDMs $\bullet$ oxygen kinetics $\bullet$ oxygen sensors

Oxygen is essential for eukaryotic cellular respiration, and cells cannot survive for prolonged periods without it. Although the air we breathe is at an ambient oxygen concentration of $21 \%$, this drops as oxygen is transported to the tissues of the body, where 'normoxic' levels are variable: oxygen concentrations in the brain, lungs and kidneys are 4.4, 5.6 and 9.5\%, respectively (Figure 1) [1]. Oxygen diffuses down a concentration gradient and thus tissues with high perfusion, for example, the kidneys have higher oxygen concentrations. Low oxygen levels, termed 'hypoxia', can disrupt normal cellular processes.

Hypoxia is usually defined as an oxygen concentration of $\leq 2 \%$ [4], and may have a number of causes. These include environmental exposure, such as high altitude and vigorous exercise, or a number of disease states. Hypoxia is a key pathological feature of cancer and cardiovascular diseases, predominantly due to localized reduction in tissue perfusion. Conversely, low oxygen conditions during early embryogenesis are essential to normal embryonic development [5].

\section{Hypoxia, HIF \& the HIF hydroxylases}

Hypoxic conditions induce an adaptive response, which occurs on both a cellular and physiological level. Cellular responses include changes in metabolism (oxidative phosphorylation to glycolysis), autophagy, and partial shut-down in high-energy consumption processes, while physiological outcomes include erythropoiesis and angiogenesis. In animals, these responses are primarily mediated by the Hypoxia Inducible transcription Factor, HIF. The HIF-mediated hypoxic response has been well characterized and recent reviews include those by Kaelin and Ratcliffe [6], Myllyharju [7] and Semenza [8].

Briefly, HIF is an $\alpha / \beta$ dimer consisting of a DNA-binding basic helix-loop-helix (bHLH) region, a PAS (Per-ARNT-Sim) domain that mediates dimerization, an oxygen-dependent degradation domain (in $\mathrm{HIF \alpha}$ ) and a $C$-terminal transactivation domain. A stable dimer
Epigenomics

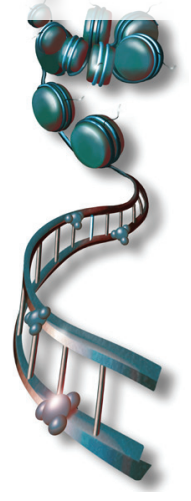

Rebecca L Hancock ${ }^{1,2}$, Kate Dunne ${ }^{1,2}$, Louise J Walport ${ }^{1}$, Emily Flashman*,*,1 \& Akane Kawamura**,*,1,2

${ }^{1}$ Chemistry Research Laboratory, 12 Mansfield Road, Oxford, OX1 3TA, UK ${ }^{2}$ Radcliffe Department of Medicine, Division of Cardiovascular Medicine, BHF Centre of Research Excellence, Wellcome Trust Centre for Human Genetics, Roosevelt Drive, Oxford, OX3 7BN, UK *Author for correspondence: emily.flashman@chem.ox.ac.uk

**Author for correspondence: akane.kawamura@chem.ox.ac.uk ${ }^{\ddagger}$ Authors contributed equally 


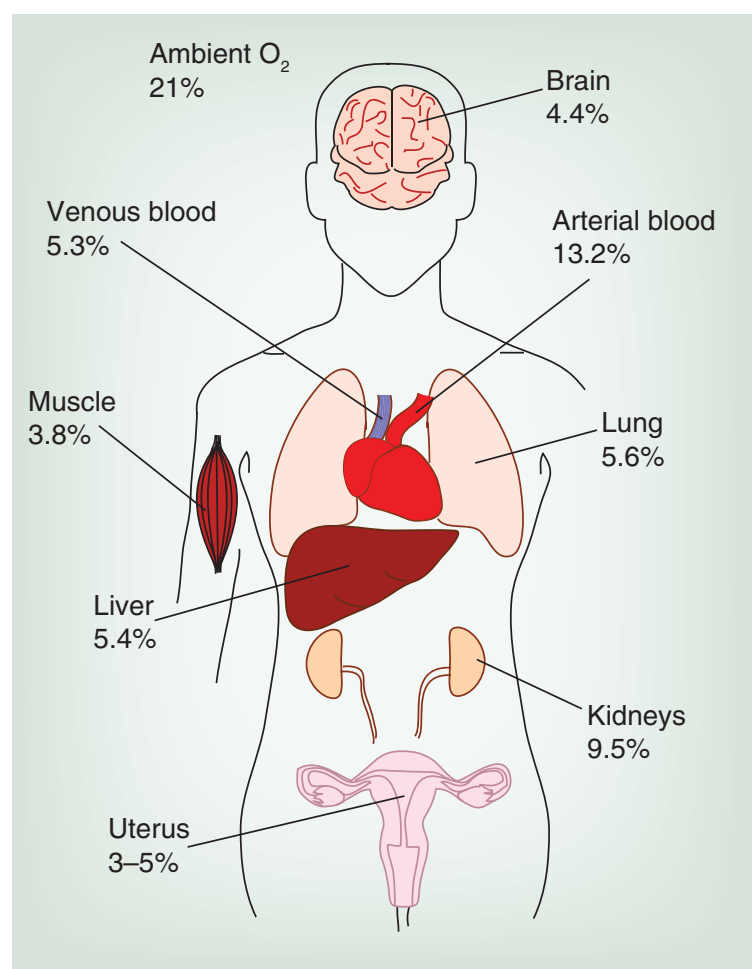

Figure 1. Oxygen concentrations as measured in selected mammalian tissues. Most tissues exist at oxygen concentrations well below ambient levels, typically $3-5 \%[1-3]$. The definition of hypoxia is an oxygen concentration of $\leq 2 \%$, while concentrations of $\leq 0.02 \%$ oxygen are defined as severe hypoxia or anoxia [4].

binds to hypoxia response elements (HREs) upstream of an array of genes that enable the hypoxic response (Figure 2A). There are several hundred known genes with HIF-binding HREs in their promoter regions, with functions as diverse as cell proliferation, angiogenic signaling and altered metabolism [9]. Responses are cell-type specific and can be mediated by HIF isomers HIF-1 or HIF-2, further tailoring targeted gene upregulation [10]. HIF is therefore referred to as the master regulator of the hypoxic response [11].

HIF levels are not directly regulated by oxygen but instead HIF $\alpha$ levels are regulated by oxygen-dependent enzymes which post-translationally hydroxylate specific residues in HIF (Figure 2A \& Figure 3B). Hydroxylation of one or both of two prolyl residues in HIF $\alpha$ (Pro-402 or Pro-564 in HIF-1 $\alpha$ ) within the $N$ - and $C$-terminal oxygen dependent degradation domains (NODD and CODD, respectively) targets HIF $\alpha$ for ubiquitination and degradation by the proteasome. Hydroxylation of an asparaginyl residue in the $C$-terminal transactivation domain (CAD) of HIF $\alpha$ (Asn-803 in HIF-1 $\alpha$ ) prevents its interaction with cotranscriptional activators. These post-translational modifications are catalyzed by the prolyl hydroxylases (PHD1-3) and Factor
Inhibiting HIF (FIH) respectively, collectively termed the HIF hydroxylases. In hypoxic conditions, the activity of these oxygen-dependent enzymes is reduced so HIF $\alpha$ levels and activity are maintained. This enables it to dimerize with HIF $\beta$ and promote the hypoxic response. The dependence of the HIF hydroxylases on oxygen has led to their classification as cellular oxygen sensors.

The HIF hydroxylases are members of the $\mathrm{Fe}(\mathrm{II}) / 2$ oxoglutarate (2OG) dependent oxygenase family of enzymes. This enzyme family is widespread in nature, catalyzing a range of oxidative reactions including hydroxylation, demethylation, desaturation, ring closure, ring cleavage, epimerization, rearrangement and halogenation [17]. There are more than 60 known 2OG oxygenases in humans, with roles in carnitine biosynthesis, epigenetic regulation, signaling and many others [18]. Structural, kinetic and spectroscopic evidence over the past two decades has revealed a conserved structure and mechanism within the 2OG oxygenases [17]. The core structural feature of these enzymes is a double-stranded $\beta$ helix (DSBH) jelly roll motif supporting an active site catalytic triad of His-XAsp/Glu- $\mathrm{X}_{\mathrm{n}}$-His that coordinates $\mathrm{Fe}$ (II) (Figure 3C). 2OG coordinates to the active site $\mathrm{Fe}$ (II) via its carboxylate and ketone oxygen atoms [19]. The 2OG oxygenases act via a conserved mechanism (Figure 3A): Prime substrate binds to an Enz.Fe(II).2OG complex causing a conformational change that weakens $\mathrm{H}_{2} \mathrm{O}$ binding to the sixth coordination position on the active site $\mathrm{Fe}(\mathrm{II})$, thus enabling oxygen to bind. Oxidative decarboxylation of 2OG to succinate and carbon dioxide results in formation of a highly reactive $\mathrm{Fe}(\mathrm{IV})=\mathrm{O}$ species which carries out the oxidation step on an unactivated C-H bond [17,19].

To date, the HIF hydroyxlases are the only members of the $2 \mathrm{OG}$ oxygenase family whose known prime physiological function is to act as cellular oxygen sensors. In order to effectively fulfill this role, the HIF hydroxylases need to sensitively respond to changes in oxygen concentration. This has been observed for the PHDs both biochemically and in cells. NODD and CODD hydroxylation in RCC4 cells [21,22] was shown to reduce over a gradient from normoxia to severe hypoxia $(<0.02 \%)$. In vitro $K_{M}$ values for oxygen for recombinant PHD2 have been reported to range between $230 \mu \mathrm{M}$ and $1.7 \mathrm{mM}$, the highest of all reported 2OG oxygenases (Table 1) [23-28], while pre-steady state kinetic investigations revealed a slow reaction of PHD2 with respect to oxygen [27,29]. These results are indicative that PHD2 activity is highly dependent on oxygen. Of note, PHD2 is considered the most important of the HIF hydroxylases in normal conditions [30], and PHD2-/- mice are embryonic lethal [31]. 
Despite being a HIF hydroxylase, FIH does not appear to be as sensitive to oxygen as PHD2; its $K_{M}$ value for oxygen is reported to be lower at $90-150 \mu \mathrm{M}$ (Table 1) [24,25], and CAD hydroxylation is maintained in RCC 4 cells exposed to an environment of $0.25 \%$ oxygen [22]. Further, FIH also functions as an ankyrin repeat domain (ARD) hydroxylase [33,34], and has been reported as having higher affinities for these alternative substrates [35], with a higher affinity for oxygen in reactions with ARDs than HIF substrates [32]. The significance of FIH in the HIF-mediated hypoxic response is therefore yet to be fully ascertained, particularly as minimal HIF-related effects were observed in FIH null mice [36].

While some studies have reported on the oxygen kinetics of other 2OG oxygenases (Table 1), including $K_{M}$ (oxygen) values for the collagen prolyl hydroxylase $\mathrm{C}-\mathrm{P} 4 \mathrm{H}$ and the mature phytanoyl-CoA hydroxylase mPAHX of $40 \mu \mathrm{M}$ [23] and $93 \mu \mathrm{M}$ [24] respectively, and fast pre-steady state kinetic activation by oxygen of TauD [37] and a viral collagen prolyl hydroxylase [38], detailed kinetic studies of other human 2OG oxygenases with respect to oxygen have so far been limited. Nevertheless, the dependence of this enzyme

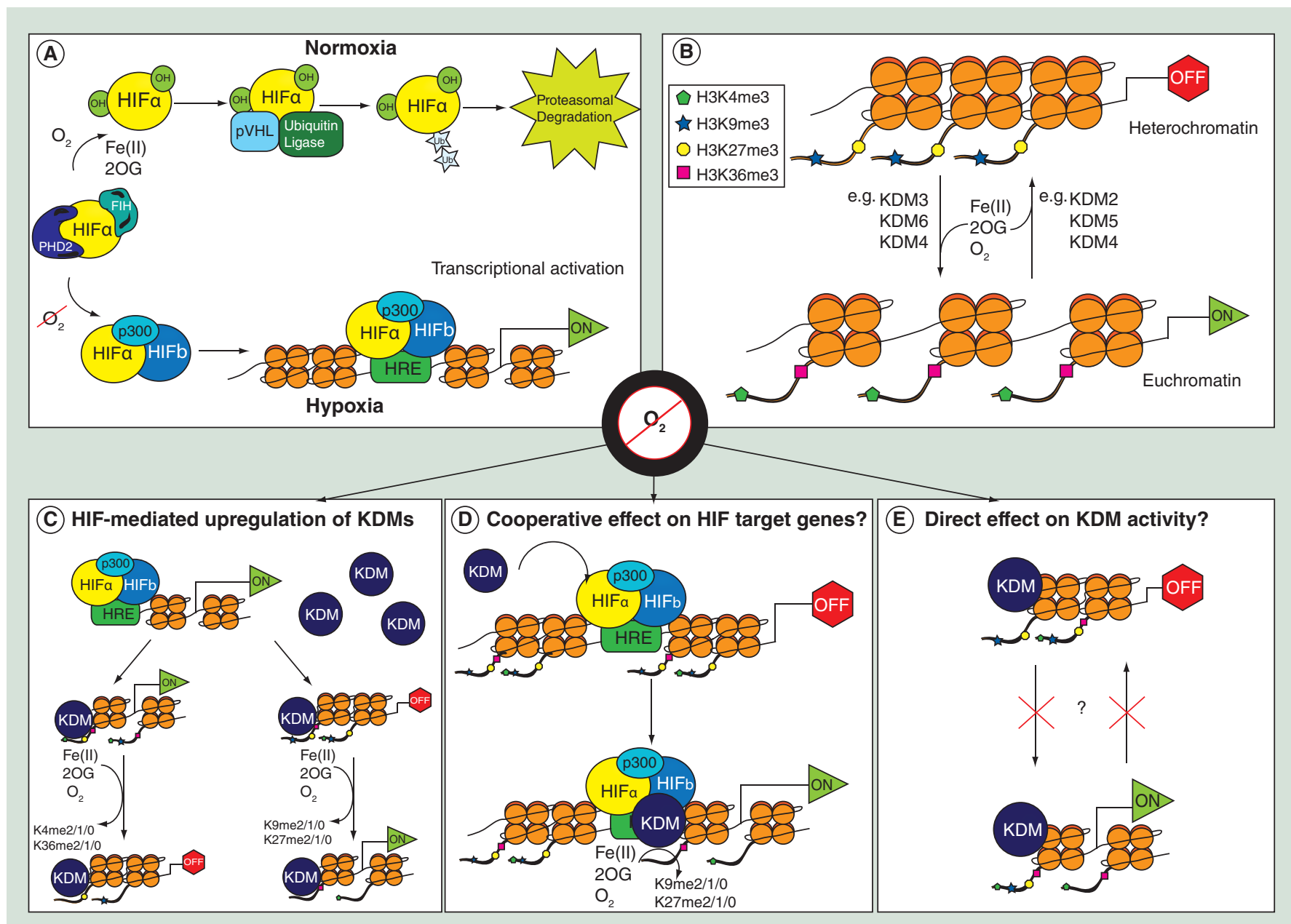

Figure 2. Transcriptional regulation by Fe(II)/2OG oxygenases. (A) The HIF-mediated hypoxic response. Under normal oxygen conditions, PHD enzymes (PHD2 is shown) and FIH hydroxylate the HIF $\alpha$ subunit, enabling binding of pVHL and ubiquitination by ubiquitin ligase, targeting HIF $\alpha$ for proteasomal degradation. In hypoxia, HIF $\alpha$ is not hydroxylated and translocates into the nucleus where it binds to the HIF $\beta$ subunit and the p300 coactivator. The HIF-p300 complex then binds to HREs at gene promoter regions, activating transcription [9].

(B) Epigenetic regulation by histone demethylases. KDMs remove methylation marks on histone tails. Changes in the methylation states of histones (and in combination with other histone modifications) can lead to either heterochromatin or euchromatin formation [12]. (C) Upregulation of the KDMs in hypoxia is proposed to increase demethylation of methylated lysine residues, altering gene expression [13]. (D) The potential for a co-operative effect between HIF and KDMs has been suggested. It is proposed that HIF recruits the KDMs to the gene locus, enabling removal of repressive marks and activation of gene expression [14,15]. (E) Direct oxygen-dependent changes in KDM activity and gene regulation [16]. HIF-independent induction of KDMs is also possible. In all cases (C-E), changing oxygen concentrations may have the potential to affect KDM activity, thus having a direct impact on transcriptional regulation.

HRE: Hypoxia response elements. 
family on oxygen and their importance in human physiology suggests that other human 2OG oxygenases may be affected by oxygen availability, with implications for hypoxic disease states. In this review we discuss the evidence that JmjC-domain containing histone lysine demethylases (JmjC-KDMs), a 2OG oxygenase family of enzymes involved in epigenetic regulation, act in an oxygen-sensitive manner, and discuss these findings with respect to dynamic changes in histone methylation patterns during development leading to a regulated transcriptional program, and dysregulation of KDMs and global methylation patterns in hypoxic disease states.

\section{Histone demethylation by the JmjC-KDMs}

In eukaryotic cells, DNA is wound around a histone octamer, which consists of two copies of each of four subunits-H2A, H2B, H3, and H4. These DNA-histone complexes, known as nucleosomes, pack together

(A)

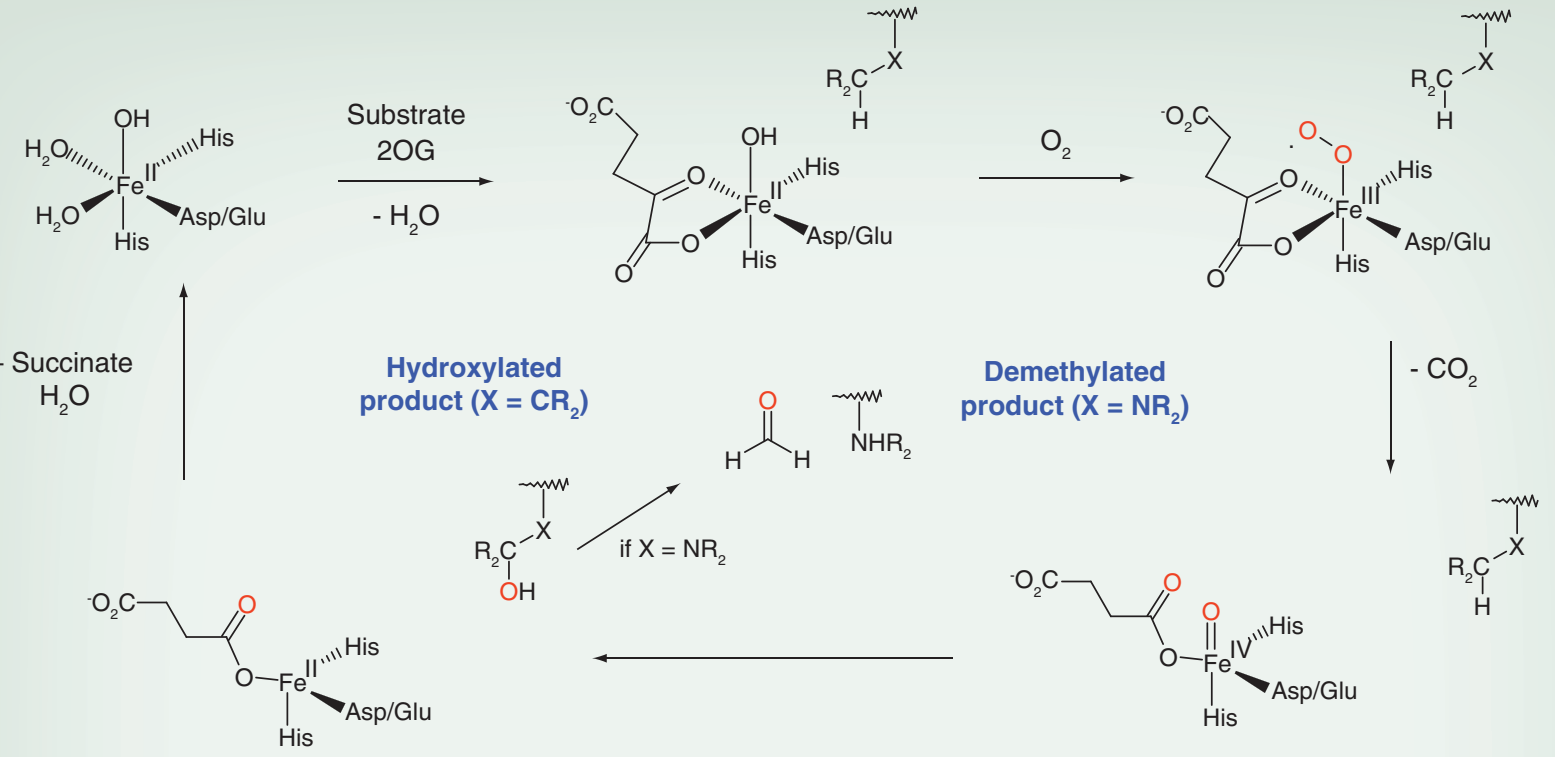

(B)<smiles>CCNC(=O)C1CCCN1CC</smiles><smiles>CCNC(=O)C1CC(O)CN1CC</smiles><smiles>CCNC(CCCCN(C)C)C(=O)CC</smiles>

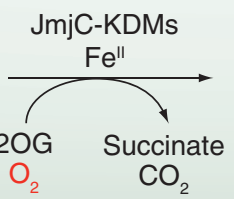<smiles>CCNC(CCCCN([10IH])CC)C(=O)CC</smiles><smiles>CC1C(=O)O[Mg]C1C(=O)O</smiles><smiles>CC(C)NC(=O)C(NC(C)C)C(N)=O</smiles>

Figure 3. Conserved structural and mechanistic features of the JmjC-KDMs and HIF hydroxylases. (A) General mechanism of the $\mathrm{Fe}(\mathrm{II}) / 2 \mathrm{OG}$ oxygenase family of enzymes. (B) PHDs (PHD1-3) hydroxylate prolyl residues 402 and 564 in the $N$ - and C-terminal Oxygen Dependent Degradation Domains of HIF $\alpha$, to produce trans-4-hydroxyproline, while FIH catalyzes trans- $\beta$ hydroxylation of asparagine 803 in the $\mathrm{C}$-terminal activation domain of $\mathrm{HIF} \alpha[9]$. JmjC-KDMs hydroxylate ${ }^{\varepsilon} \mathrm{N}$-methylated lysine residues in the $\mathrm{N}$-terminal tails of histone proteins, to produce an unstable hemiaminal intermediate, which generates formaldehyde and demethylated lysine [51].(C) Ribbon representation of KDM4A, FIH and PHD2 (PDB ID: 2OX0, 2XUM, 3HQR respectively) showing double-stranded $\beta$-helix (teal) and $\alpha$-helices (white). Stick representation of active site His-X-Asp/Glu-Xn-His Fe(II) binding motif residues (magenta, pink, purple) common to this class of enzymes. $\mathrm{N}$-oxalylglycine, an inhibitory $20 \mathrm{G}$ analog is shown bound in the $20 \mathrm{G}$ binding site of these enzymes (yellow).

2OG: 2-oxoglutarate. 
(C)

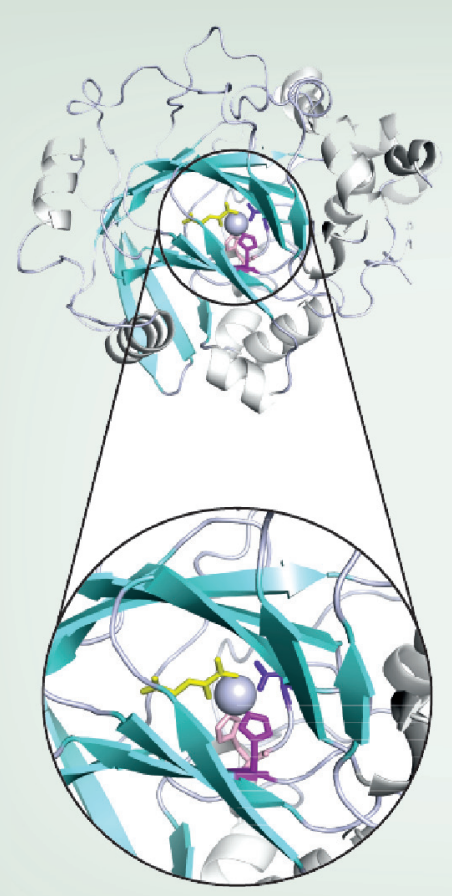

KDM4A

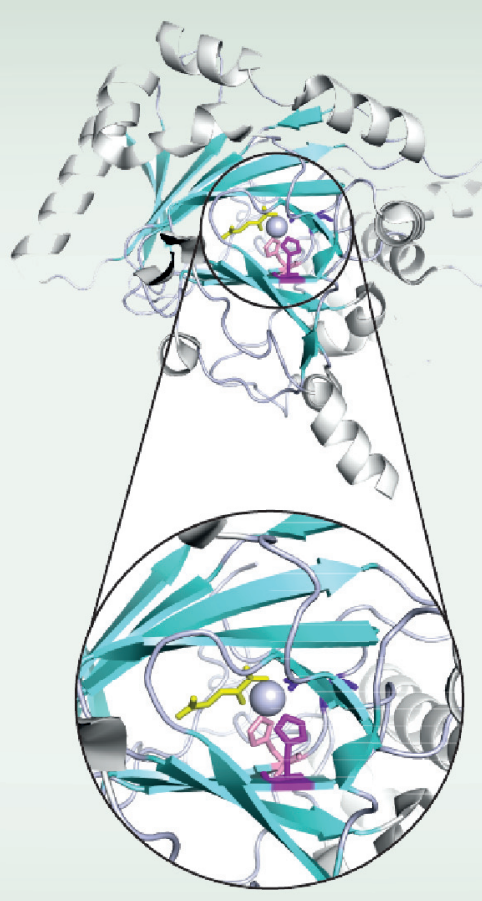

$\mathrm{FIH}$

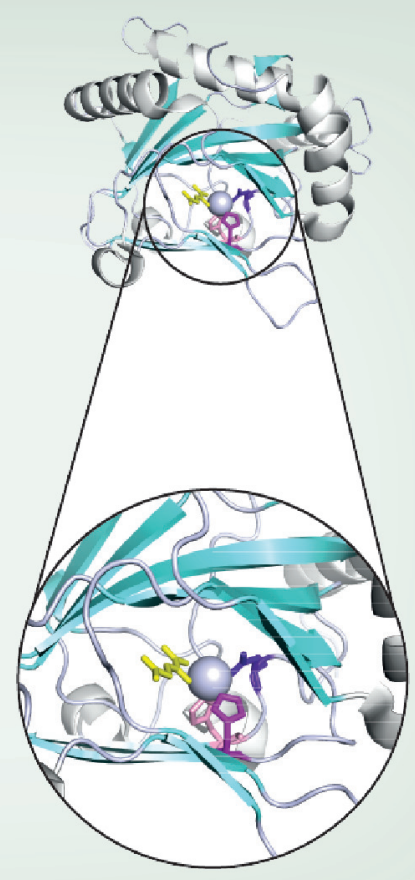

PHD2

Figure 3. Conserved structural and mechanistic features of the JmjC-KDMs and HIF hydroxylases (cont.). (A) General mechanism of the $\mathrm{Fe}(\mathrm{II}) / 2 \mathrm{OG}$ oxygenase family of enzymes. (B) PHDs (PHD1-3) hydroxylate prolyl residues 402 and 564 in the $N$ - and C-terminal Oxygen Dependent Degradation Domains of HIF $\alpha$, to produce trans-4-hydroxyproline, while FIH catalyzes trans- $\beta$ hydroxylation of asparagine 803 in the C-terminal activation domain of HIF $\alpha[9]$. JmjC-KDMs hydroxylate ${ }^{\circledR} N$-methylated lysine residues in the $N$-terminal tails of histone proteins, to produce an unstable hemiaminal intermediate, which generates formaldehyde and demethylated lysine [51].(C) Ribbon representation of KDM4A, FIH and PHD2 (PDB ID: 2OX0, 2XUM, 3HQR respectively) showing double-stranded $\beta$-helix (teal) and $\alpha$-helices (white). Stick representation of active site His-X-Asp/Glu-Xn-His Fe(II) binding motif residues (magenta, pink, purple) common to this class of enzymes. $\mathrm{N}$-oxalylglycine, an inhibitory $20 \mathrm{G}$ analog is shown bound in the $20 \mathrm{G}$ binding site of these enzymes (yellow). 20G: 2-oxoglutarate.

to form chromatin. Chromatin can take an open form, euchromatin, which allows transcriptional machinery to access DNA, or a closed form, heterochromatin, in which the DNA is inaccessible (Figure 2B) [12]. Dynamic covalent modifications to DNA and the unstructured $N$-terminal tails of histones alter chromatin structure thus modulating gene expression and forming the basis of epigenetic regulation [12]. Multiple post-translational modifications are found on histone tails, including acetylation, phosphorylation, ubiquitination and methylation [39].

Whether a given histone modification is activating or repressive is dependent on which residue (and originating histone subunit) is modified, the type of modification, the degree of modification (in the case of methylation) and the combination of these modifications - this is also referred to as the histone code [40]. Histone tail lysines may be mono-, di- or tri-methylated (Figure 3B). In general, methylation at $\mathrm{H} 3 \mathrm{~K} 4, \mathrm{H} 3 \mathrm{~K} 36$ and $\mathrm{H} 3 \mathrm{~K} 79$ is associated with active genes, whereas methylation at $\mathrm{H} 3 \mathrm{~K} 9, \mathrm{H} 3 \mathrm{~K} 27$ and H4K20 correlates with repressed genes [41]. The distribution of histone methylation across the genome is an important factor in gene transcription. For example, in active genes, H3K4me3 is generally enriched in promoter and transcriptional start sites (TSS), whereas H3K79 and H3K36 methylations are abundant within the gene body itself. On the other hand, in repressed genes, $\mathrm{H} 3 \mathrm{~K} 27 \mathrm{me} 3$ is generally enriched in the promoter region, and $\mathrm{H} 3 \mathrm{~K} 9 \mathrm{me} 2 / 3$ and H4K20 marks are uniformly distributed throughout the gene [42]. Both activating (H3K4 methylation) and repressive marks (H3K27 methylation) are also found to co-exist as bivalent chromatin in embryonic stem cells (ESCs) [43].

Histone lysine methylation is dynamically regulated by histone methyltransferases (KMTs) and histone demethylases (KDMs). Methylation of lysine residues is carried out by histone KMTs, a family of enzymes that utilize $S$-adenosylmethionine (SAM) as a methylgroup donor, and include the SET domain family [44,45] and DOT1L [46]. Methylation is removed by histone demethylases (KDMs). Two mechanistically distinct 
Table 1. Differential sensitivity of $20 \mathrm{OG}$ oxygenases to oxygen in vitro.

\begin{tabular}{|c|c|c|c|}
\hline Enzyme & $K_{M}\left(\mathrm{O}_{2}\right) / \mu \mathrm{M}$ & Substrate & Ref. \\
\hline PHD2 $_{181-426}$ & $230-1746$ & HIF-1 $\alpha_{556-574}$ CODD & {$[24]^{\dagger},[23]^{\ddagger},[27]^{\S},[28]^{\#}$} \\
\hline $\mathrm{C}-\mathrm{P} 4 \mathrm{H}$ & 40 & Pro-Pro-Gly & {$[23]^{\ddagger}$} \\
\hline mPAHX & $93 \pm 43$ & Isovaleryl CoA & {$[24]^{\dagger}$} \\
\hline TauD & $76 \pm 17$ & Taurine & {$[24]^{\dagger}$} \\
\hline $\mathrm{FIH}$ & $90-150$ & HIF- $1 \alpha_{788-822}$ CAD & {$[24]^{\dagger},[25]^{\ddagger}, \mathrm{H}$ Tarhonskaya ${ }^{\S}$ [Unpublished Data] } \\
\hline $\mathrm{FIH}$ & $110 \pm 73$ & HIF- $2 \alpha_{832-866}$ CAD & {$[24]^{\dagger}$} \\
\hline $\mathrm{FIH}$ & $100 \pm 10$ & HIF- $2 \alpha_{832-866}$ CAD & H Tarhonskaya ${ }^{\S}$ [Unpublished Data] \\
\hline $\mathrm{FIH}$ & $10-120$ & Non-HIF substrates & H Tarhonskaya ${ }^{\S}$ [Unpublished Data] [32] \\
\hline $\mathrm{KDM}_{4} \mathrm{~A}_{1-359}$ & $57 \pm 10$ & $\mathrm{H}_{7-14} \mathrm{~K} 9 \mathrm{me} 3$ & {$[26]^{\dagger}$} \\
\hline $\mathrm{KDM} \mathrm{CC}_{1-366}$ & $158 \pm 13$ & $\mathrm{H}_{7-14} \mathrm{~K} 9 \mathrm{me} 3$ & {$[26]^{\dagger}$} \\
\hline $\mathrm{KDM}_{4-337}$ & $197 \pm 16$ & $\mathrm{H}_{7-14} \mathrm{~K} 9 \mathrm{me} 3$ & {$[26]^{\dagger}$} \\
\hline $\mathrm{KDM} \mathrm{E}_{1-337}$ & $>93$ & $\mathrm{H} 3_{7-14} \mathrm{~K} 9 \mathrm{me} 3$ & {$[20]^{\S}$} \\
\hline \multicolumn{4}{|c|}{ 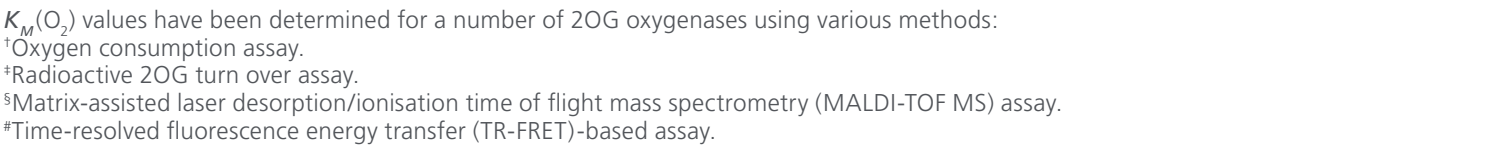 } \\
\hline
\end{tabular}

families of histone demethylases have been identified: the LSD1 family of flavin-dependent monoamine oxidases (KDM1) and the JmjC-KDMs (Figure 2B). The JmjC-KDMs, the larger of the two KDM families, are members of the $2 \mathrm{OG}$ oxygenase family. Structural studies and sequence alignments reveal that all JmjC$\mathrm{KDM}$ s contain a catalytic JmjC-domain with a conserved core DSBH structural motif, as exemplified by the structure of KDM4A in Figure 3C [47-49]. Evidence to date, including structural and spectroscopic observations of Enz.Fe(II).2OG.substrate complexes and kinetic investigations, indicates that the JmjC-KDMs conform to the proposed 2OG consensus mechanism (Figure $3 \mathrm{~A} \& \mathrm{~B}$ ) [20,50]. The prime substrate of the JmjC$\mathrm{KDMs}$ is the unactivated $\mathrm{C}-\mathrm{H}$ bond of ${ }^{8} N$-methyl lysine residues on histones. The JmjC-KDMs catalyse hydroxylation of this bond, resulting in an unstable hemiaminal intermediate that fragments to produce the demethylated lysine residue and formaldehyde (Figure 3B).

The JmjC-KDMs have been categorized into 7 KDM subfamilies (KDM2-8) based on the JmjCdomain sequence homology and their demethylase activities (Table 2) [51,52]. Different JmjC-KDMs exhibit different methylation state and histone substrate specificities [52,53]. While KDM2/3/7 subfamilies are diand monomethyl demethylases, KDM4-6/8 can also remove tri-methyl marks (Table 2). Some KDM subfamilies are highly specific for particular histone substrates whereas some have overlapping substrate selectivities. For example, the KDM5 and KDM6 members are specific for methylated $\mathrm{H} 3 \mathrm{~K} 4$ and $\mathrm{H} 3 \mathrm{~K} 27$, respec- tively. Further, all KDM4 members can demethylate H3K9, but KDM4A-C can also demethylate H3K36 and H1.4K26 (Table 2) [51]. Most, but not all, JmjC$\mathrm{KDMs}$ have domains in addition to the catalytic domain. Many contain binding domains (e.g., CXXC DNA-binding domain, Plant homeodomain [PHD] fingers, Tudor domains), which assist KDM recruitment to certain chromatin regions and/or enable substrate specificity. For instance, the PHD-finger domain of PHF8/KDM7B binds to H3K4me3 and promotes removal of the $\mathrm{H} 3 \mathrm{~K} 9 \mathrm{me} 2$ mark via the catalytic domain [54]. Furthermore, JmjC-KDMs have been found in large complexes with multiple proteins including complementary KMTs and other epigenetic proteins [55]. Combinations of various marks on histone tails provide functional crosstalk, and the JmjC-KDMs and their associated complexes are key players in fine-tuning transcriptional regulation.

\section{Histone methylation \& hypoxia}

Multiple studies demonstrate that exposure to hypoxia can alter the epigenetic landscape at the chromatin level in cells [14,16,64-70] (Table 3). Similar changes to epigenetic marks, including histone lysine methylation, have been observed in development and in disease states where hypoxia is known to be an important feature. The mechanisms for these alterations appear to be both direct (via altered JmjC-KDM activity or expression levels) and indirect (in a HIFmediated manner): some JmjC-KDMs are known to be direct targets of HIF and thus their levels are upregulated in hypoxia. These include KDM3A, 
Table 2. Histone substrate selectivity of JmjC-KDMs in cells.

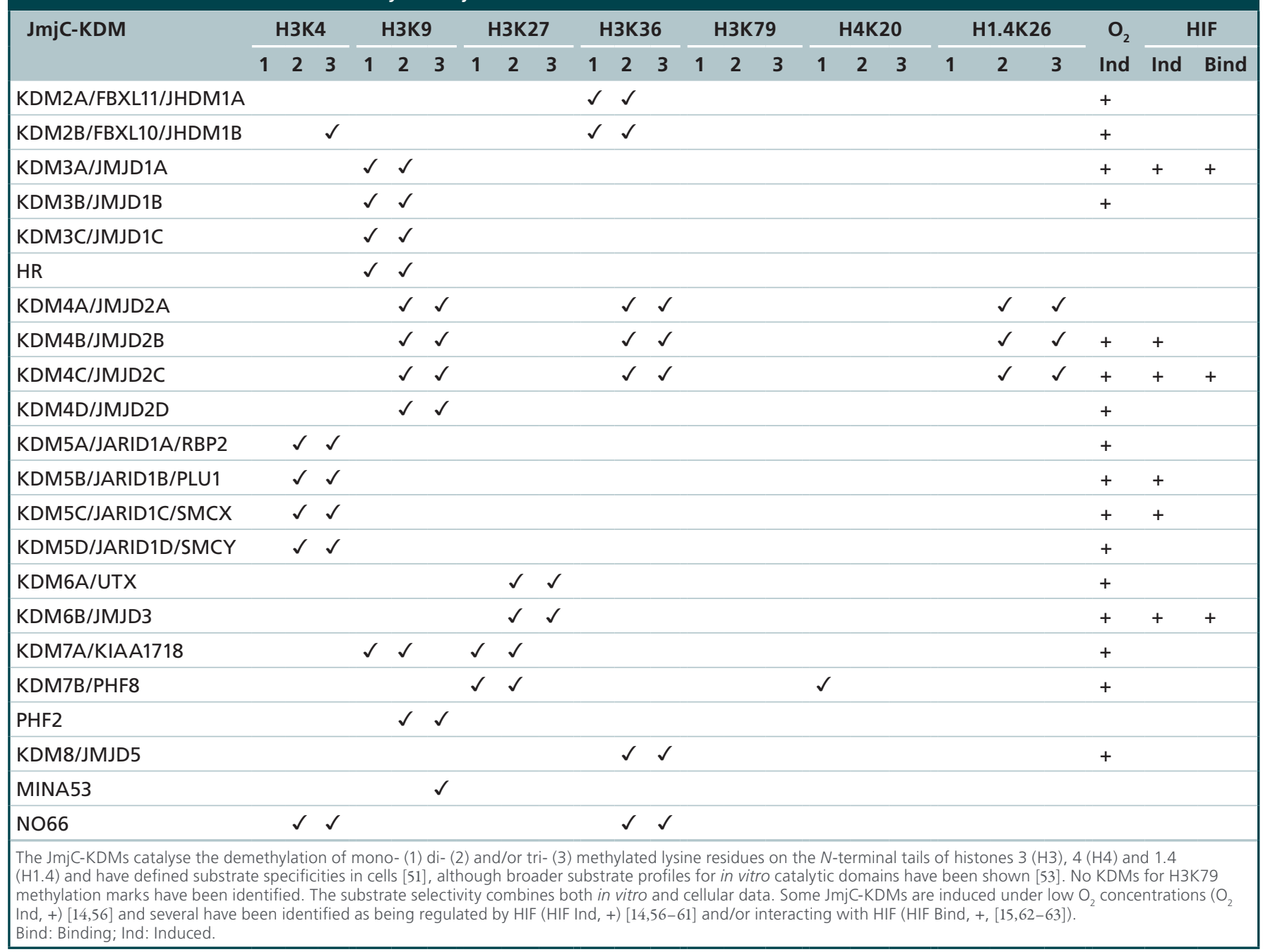

KDM4B, KDM4C, KDM5B and KDM5C [14,57-61], and more recently KDM6B (Table 2) [56]. However, other JmjC-KDMs have been found to be upregulated in hypoxia (at the mRNA level) but thus far have not been identified as HIF target genes [14,62,71]. Intriguingly, Beyer et al. demonstrated differential sensitivity to hypoxia of overexpressed KDM3A and KDM4B in HeLa cells incubated at $0.2 \%$ oxygen. Demethylation of $\mathrm{H} 3 \mathrm{~K} 9 \mathrm{me} 3$ by KDM4B was attenuated, while the activity of KDM3A was maintained under the same conditions [57]. It has been proposed that the upregulation of KDMs acts as a compensatory mechanism whereby increased levels of these enzymes compensate for their reduced activity in depleted oxygen conditions [14,57]. However, the disparity in apparent oxygen sensitivity of two HIF-target JmjC-KDMs revealed in this study suggests that the relationship between HIF and the JmjC-KDMs may be more complex. Of note, both KDM4C and KDM6B have been shown to bind to HIF in a potential coactivating role (Table $2 ;[15,72]$ ), and the HIF-mediated upregulation of several JmjC-KDMs in cancer has been well documented (see below).

Given their absolute requirement for oxygen and relationship to the HIF hydroxylases, the question has been raised as to whether the JmjC-KDMs could be similarly sensitive to oxygen availability, in other words, whether their activity diminishes in hypoxic conditions. Biochemical data to validate the sensitivity of JmjC-KDM activity with respect to oxygen are to date limited, partly due to the relatively recent development of robust assays for their activity (including with respect to oxygen). $K_{M}$ values for oxygen have been reported for KDM4A, KDM4C and KDM4E at 57, 157 and $197 \mu \mathrm{M}$, respectively (Table 1), measured using an oxygen-consumption assay with an 8-mer peptide substrate [26]. KDM4E activity measured over a range of oxygen concentrations, 0-20\%, detected by mass spectrometry analysis of demethylation of an 8-mer peptide 
Table 3. Changes to histone methylation status observed in hypoxia.

\begin{tabular}{|c|c|c|c|c|c|}
\hline Cell line & $\% \mathrm{O}_{2}$ & $\begin{array}{l}\text { Changes to global } \\
\text { methylation }\end{array}$ & $\begin{array}{l}\text { Gene locus and change } \\
\text { in expression levels }\end{array}$ & $\begin{array}{l}\text { Altered methylation } \\
\text { status at promoter }\end{array}$ & Ref. \\
\hline \multirow[t]{2}{*}{ A549 } & \multirow[t]{2}{*}{ NS } & H3K9me2 $\uparrow$ & \multirow[t]{2}{*}{-} & \multirow[t]{2}{*}{-} & \multirow[t]{2}{*}[64]{} \\
\hline & & H3K9me3 $\uparrow$ & & & \\
\hline Fetal lung type II & 2.0 & H3K9me2 $\uparrow$ & $S P-A \uparrow$ & H3K9me2 $\uparrow$ & [65] \\
\hline A549, HOS, HEK 293 & 0.5 & H3K9me2 $\uparrow$ & $M L H 1 \downarrow, D H F R \downarrow$ & H3K9me2 $\uparrow$ & [66] \\
\hline \multirow[t]{6}{*}{ Hepa1-6 } & \multirow[t]{6}{*}{0.2} & H3K4me2 $\uparrow$ & $A F P \downarrow, A L B \downarrow$ & H3K9me2 $\uparrow$ & \multirow[t]{6}{*}[67]{} \\
\hline & & H3K4me3 $\uparrow$ & \multirow[t]{5}{*}{$E G R 1 \uparrow$} & H3K27me2 $\uparrow$ & \\
\hline & & H3K79me2 $\uparrow$ & & H3K9me2 $\downarrow$ & \\
\hline & & H3K27me3 $\downarrow$ & & H3K27me2 $\downarrow$ & \\
\hline & & H3K9me2 $\downarrow$ & & & \\
\hline & & H3K4me1 $\uparrow$ & & & \\
\hline \multirow[t]{4}{*}{ HepG2 } & \multirow[t]{4}{*}{$0.1-5$} & H3K4me2 $\uparrow$ & \multirow[t]{4}{*}{-} & \multirow[t]{4}{*}{-} & \multirow[t]{4}{*}[14]{} \\
\hline & & H3K4me3 $\uparrow$ & & & \\
\hline & & H3K9me2 $\uparrow$ & & & \\
\hline & & H3K36me3 $\uparrow$ & & & \\
\hline BEAS-2B, A549 & 1.0 & H3K4me3 $\uparrow$ & - & - & [68] \\
\hline \multirow[t]{3}{*}{ RAW264.7 } & & H3K9me2 $\uparrow$ & \multirow[t]{3}{*}{$C C L 2 \downarrow, C C R 1 \downarrow, C C R 5 \downarrow$} & H3K9me2 $\uparrow$ & \multirow[t]{3}{*}{ [16] } \\
\hline & & H3K9me3 $\uparrow$ & & H3K9me3 $\uparrow$ & \\
\hline & & H3K36me3 $\uparrow$ & & & \\
\hline McA-RH7777 & 1 or 5 & H3K9me3 $\uparrow$ & - & - & [69] \\
\hline
\end{tabular}

substrate confirmed a graded response to oxygen over this range [20]. Pre-steady state kinetic analyses of KDM4E activity with oxygen revealed a slow rate of oxygen activation similar to that observed for PHD2 [20]. These published data (Table 1) indicate differential sensitivity of some JmjC-KDMs toward oxygen suggesting the potential for some, though likely not all, of the JmjC-KDMs to act in an oxygen-sensitive manner $[20,26]$.

\section{Hypoxia \& development}

The gestation environment is hypoxic, and oxygen concentration varies during development (Figure 4) [73,74]. One single cell, the zygote, gives rise to all cells of an ordered multicellular organism. This is achieved through differentiation, where spatiotemporal regulation of gene expression under epigenetic control causes pluripotent cells to differentiate through increasingly differentiation-restricted cell types to yield a wide range of specialized cell lineages. Differentiation can be regulated by intracellular genetic mechanisms and by the extracellular microenvironment. It is possible that external stimuli, such as oxygen tension, and genetic modulators, such as histone modifications, may interact in a regulatory manner to drive development.

Hypoxia has an essential regulatory role in normal development. Insults to the normal gestational oxygen conditions, both hypoxic and hyperoxic, lead to morphological defects [5,82-83], and oxygen tension has been shown to regulate differentiation potential in various embryonic and induced stem cell models [84]. Incubation of embryos at low oxygen during in vitro fertilization has been shown to improve both embryo quality and clinical outcome, possibly because this mimics the conditions in vivo [85].

\section{TrX, polycomb \& bivalency, \& their roles in development}

In undifferentiated cells pluripotency genes are activated, while lineage-associated genes are repressed. Upon differentiation pluripotency genes become repressed, while lineage-associated genes are activated, yielding a specialized cell phenotype [86]. Bivalency, the co-localization of one activating and one repressing histone modification, is one potential mechanism by which histone methylation states regulate early development. Bivalent histone states (H3K4me3 and 


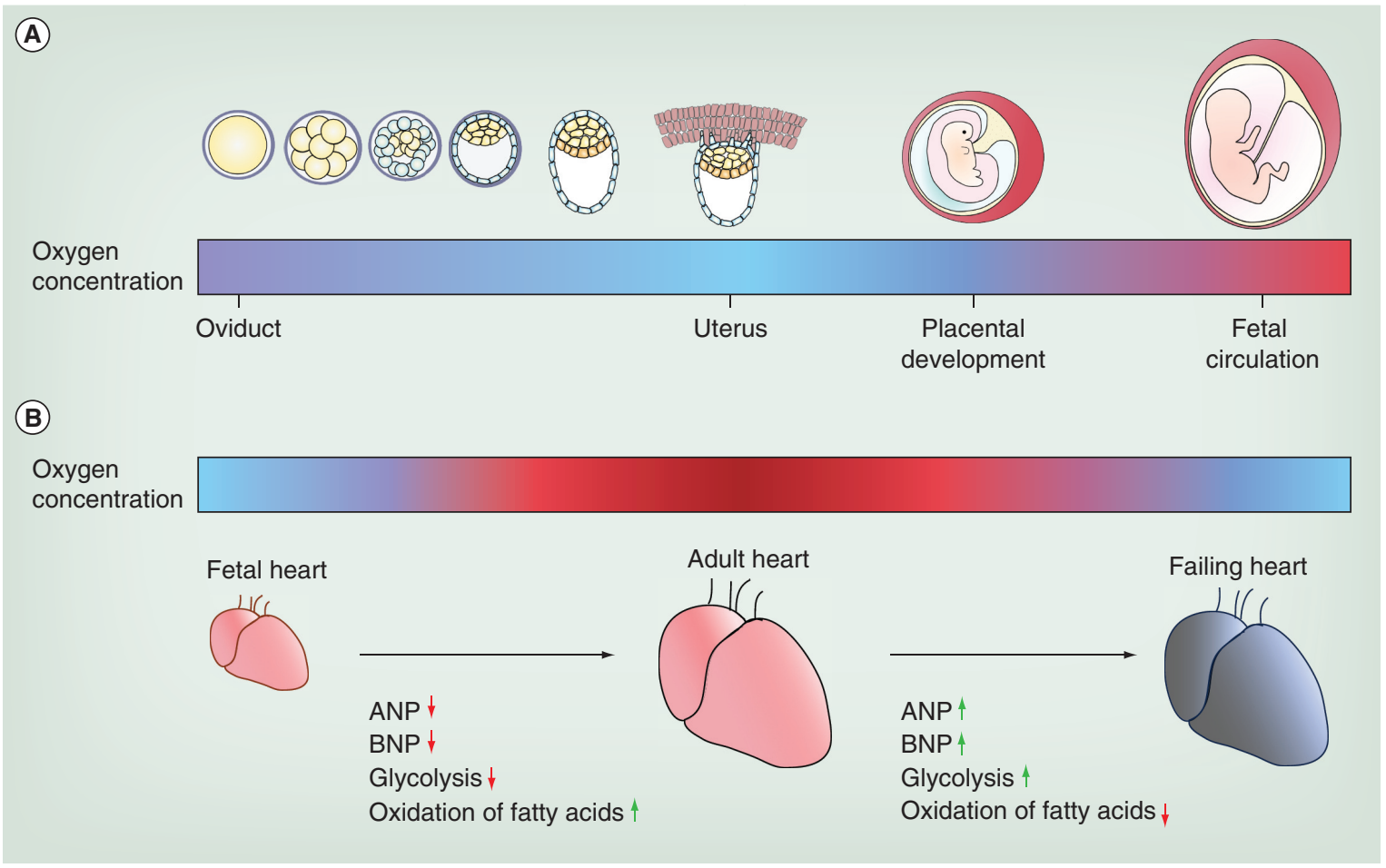

Figure 4. Oxygen environments in development and disease. (A) Oxygen tension in the oviduct and uterus varies between $2-8 \%$. Oxygen available to the early embryo is limited by diffusion from these tissues. After fertilization in the oviduct the embryo migrates, experiencing a decreasing oxygen gradient, to the uterus [3]. Even after placental development, oxygen conditions are still low as the placenta acts as a barrier to oxygen [75]. It is not until fetal circulation is established that oxygen available to the fetus increases [76]. (B) The different oxygen environments experienced by the fetal, adult and diseased heart. The fetal heart exists in a hypoxic environment [77], with a postnatal transition into a more oxygenated state [78] accompanied by remodeling and changes in gene expression. Many cardiovascular disease states are characterized by hypoxia, and the failing heart possesses a gene expression profile similar in many ways to that of the fetal heart [79-81].

H3K27me3) have been identified in a number of studies in human ESC, murine and zebrafish models of development $[43,87-92]$.

Bivalent states are maintained at developmental target genes. The H3K27me3 mark represses expression of the lineage gene, protecting pluripotency, while the H3K4me3 mark 'poises' target genes for activation enabling rapid expression upon differentiation. Upon differentiation, the bivalent histone state is resolved yielding either a stable activate or stable repressive histone state [86]. Bivalent histone states are established and resolved by antagonistic Polycomb group (PcG) and Trithorax group (trxG) complexes, which contain specific methyltransferases for depositing H3K27me3 and $\mathrm{H} 3 \mathrm{~K} 4 \mathrm{me} 3$, respectively. The PcG and trxG complexes also possess other components involved in recruitment to genomic loci, chromatin condensation and other histone modifications. PcG and trxG mediated deposition of both marks results in a bivalent state, but this equilibrium is disturbed by activating stimuli. KDMs are then recruited to remove either $\mathrm{H} 3 \mathrm{~K} 27 \mathrm{me} 3$ or $\mathrm{H} 3 \mathrm{~K} 4 \mathrm{me} 3$ resulting in stable gene activation or repression [93].
Bivalency has been indicated in control of Hox genes, [94] cardiac differentiation potential and tooth development [92,95]. Indeed, KDM6s have been associated with decreased H3K27me3 levels and activation of Hox genes during development [96], while KDM5A regulates Hox gene expression and is recruited by $\mathrm{PcG}$ to developmental genes in murine ESCs [97].

\section{JmjC-KDMs \& development}

The JmjC-KDMs are thought to regulate development by maintaining or removing histone lysine methylation states which repress or activate gene expression, such as $\mathrm{H} 3 \mathrm{~K} 27 \mathrm{me} 3$ or $\mathrm{H} 3 \mathrm{~K} 4 \mathrm{me} 3$, respectively. Histone lysine methylation is a relatively stable histone modification and thus is ideally suited to maintain gene expression patterns and cell identity during development [98].

A considerable number of studies have linked KDMs to embryogenesis and post-implantation development including organogenesis [98-100]. Spatiotemporal expression profiles of JmjC-KDMs have been characterized in murine and bovine embryos [101,102]. Deletion of specific JmjC-KDMs in numerous developmental models results in embryonic lethality and 
morphological defects [98-100]. Additionally, JmjCKDM mutations have been linked to several developmental syndromes [103-105]. Various studies have linked each of the JmjC-KDM subfamilies to developmental roles (see Pedersen and Helin review [99]).

Despite a number of studies, the role of the KDM2 subfamily in development is poorly understood [98]. Homozygous knockout of KDM2B in mice causes partial peri- and post-natal death, with pups displaying exencephaly and an increased number of mitotic neural progenitor cells [106]. KDM2A knockout in mice results in embryonic lethality, downregulation of PcG, decreased cell proliferation and increased apoptosis [107]. In cattle, a KDM2B missense mutation causes congenital multiorgan developmental dysplasia $[108,109]$. KDM3A regulates male sex determination during development in mice; KDM3A-mediated demethylation of $\mathrm{H} 3 \mathrm{~K} 9$ leads to transcription of Sry, a 'master switch' of sex determination [110]. KDM3A also has a role in maintaining pluripotency in ESCs by demethylation of H3K9 leading to expression of pluripotency factors. The same study found that KDM4C also regulates maintenance of pluripotency via $\mathrm{H} 3 \mathrm{~K} 9$ demethylation [111]. KDM4A and KDM4B are essential to Drosophila development and mediate ecdysteriod hormone signaling leading to transcriptional activation of ecdysone response genes [112].

Key roles in neural development have been identified for KDM5B and KDM5C. KDM5B is essential to neural differentiation of ESCs [113] and deletion caused defects in eye and cranial nerve [114]. Mutations in KDM5C have been found in patients with X-linked mental retardation and epilepsy [15], and studies in zebrafish have identified potential roles in brain patterning and neuronal survival [116].

Homozygous deletion of KDM6A causes embryonic lethality in mice, C. elegans and Drosophila in a sexspecific manner [117], while in humans, constitutional KDM6A mutations have been identified as a cause of Kabuki syndrome [103]. KDM6A and KDM6B have key roles in neural and cardiac development. KDM6B is upregulated during differentiation of ESC to neuronal lineages [118], and overexpression of KDM6B in neural progenitor cells (NPCs) lead to expression of neuronal genes [119]. Invivo experiments in chick neural tubes found that KDM6B acts with SMAD to co-activate the neural gene program [120]. KDM6A is essential for retinoic acid induced neural differentiation in an ESC model [121]. KDM6A and KDM6B null ESCs have reduced capacity for cardiac lineage commitment $[122,123]$. Severe cardiac defects and embryonic lethality is seen in KDM6A deficient mice, accompanied by reduced expression of key cardiac genes, while KDM6B deficient embryos die at the blastocyst stage [122,123].
Within the KDM7 cluster, PHF8 (KDM7B) has been found to be important in neural development [124]. Mutations in PHF8, including some which are catalytically inactivating, have been identified in patients with X-linked mental retardation and cleft lip/palate [125]. PHF8 deletion in zebrafish leads to animals with fewer neurons and craniofacial alterations [124,126] and loss of the PHF8 PHD finger in C. elegans causes impaired locomotion [127]. In chickens, KDM7A/KIAA1718 promotes neural induction [128].

Understanding the role of the JmjC-KDMs in the hypoxic environment of development is likely to be useful in the context of hypoxic disease states. Uncovering the mechanisms by which these enzymes may be regulating pluripotency and differentiation may be useful in the production of therapeutic cell populations. Both oxygen tension and the JmjC-KDMs have regulatory roles in development, and there is a need to characterize the relationship between these two influences. Further, as stated above, HIF regulates expression of a number of JmjC-KDMs and thus it is likely that HIF-mediated expression of JmjC-KDMs is significant during development (for a more detailed discussion of HIF and development see Dunwoodie, 2009 [73]).

\section{Cancer \& hypoxia}

Hypoxia is a common feature of solid tumors. As tumors grow, they surpass the diffusion limits of the local blood supply, resulting in regions where the concentration of oxygen is severely reduced relative to normal tissue. This leads to stabilization of HIF to activate the hypoxic transcriptional response (including angiogenesis), and a shift in energy metabolism from oxidative phosphorylation to glycolysis (known as the 'Warburg effect' [129], a recognized hallmark of cancer). The HIF response can partially restore oxygen supply to tumors, but nevertheless, oxygen supply can fluctuate and cells adapt to an ever-changing microenvironment. While the HIF system is the major factor affecting gene expression changes associated with oxygen concentrations, it is feasible that epigenetic changes, both dependent and independent of HIF pathways, also have significant implications in transcriptional regulation and cellular adaptation at different oxygen concentrations in disease (reviewed in Kaelin and Ratcliffe 2008 [6]).

\section{Cancer \& JmjC-KDMs.}

Many epigenetic proteins are dysregulated or mutated in cancers [130]. Aberrant gene expression and epigenetic patterns are associated with cancer occurrence and progression, often associated with poor prognosis [131]. 
Emerging evidence suggests that many KDMs are implicated in tumor growth, with a number of KDMs identified to be oncogenes (see Højfeldt et al. for a recent review on KDMs and cancer [52]).

Of the HIF-regulated JmjC-KDMs, KDM3A has been implicated in numerous cancers including bladder cancer [132], renal cell carcinoma [13], hepatocellular carcinoma [133,134] and colorectal cancer $[13,135]$. The KDM4s play key roles in the cell cycle and proliferation $[136,137]$ and have been strongly linked to cancer. KDM4A and B are overexpressed in breast, prostate, colorectal, bladder and gastric cancers, and KDM4B, which associates with the androgen receptor (AR) and the estrogen receptor (ER), is being actively pursued as a prostate and breast cancer target [138]. KDM4C is amplified in squamous cell carcinoma [136] and required for growth in many cancer cells including esophageal [136], prostate [139] and breast [140] cancers. KDM4A and C have been shown to form a complex with the AR in prostate cancer cells and co-operatively demethylate the repressive histone marks (H3K9me3/me2) to activate transcription of androgen receptor target genes responsible for tumor proliferation [139,141-142]. KDM5B is required for growth of breast cancer cells [143] and of slowcycling melanoma cells [144], and is linked to prostate cancer malignancy [145]. KDM5A/B are found to be overexpressed in multiple cancer cells, including cervical, gastric, lung, bladder and breast cancer [146]. KDM6B is highly expressed in T-cell acute lymphoblastic leukemia (T-ALL) cells and is essential for the initiation and maintenance of T-ALL [147]. It is also upregulated in renal cell carcinoma [148].

It is possible that, for at least some JmjC-KDMs, their association with cancer may be related to hypoxia. Recently, KDM3A, KDM4B/C and KDM5B have been identified as HIF target genes and are thus upregulated in hypoxic conditions (Figure 2C) [14,57-59,61]. This hypoxic JmjC-KDM induction is found to further amplify HIF target gene expression, either by direct interaction with HIF or by separate promoter binding and demethylation (Figure 2E). In hypoxic conditions, KDM3A removes $\mathrm{H} 3 \mathrm{~K} 9$ methylation from the promoters of HIF target genes, such that KDM3A activity is required for their full hypoxic induction [13]. Consistent with this, significant differences in gene expression profiles are observed in KDM3A knockout mouse ESCs under hypoxia [149]. Hypoxic induction of KDM3A in several cancer cell lines enhanced cell proliferation and tumor growth via transcriptional activation of several tumorigenic and proliferative genes [134]. Hypoxia has been shown to increase expression of prostate-specific antigen (PSA) in LNCaP cells, via direct interaction of KDM3A, HIF- $1 \alpha$ and the AR resulting in recruitment of KDM3A to the PSA enhancer region [63].

$\mathrm{KDM} 4 \mathrm{C}$ has been shown to facilitate the hypoxic response by directly interacting with HIF and thereby enhancing its transcriptional activity. KDM4C binds directly to HIF-1 $\alpha$, which directs it to HIF target genes, promoting $\mathrm{H} 3 \mathrm{~K} 9$ demethylation of the HRE and gene induction. The histone demethylation activity of KDM4C is required for HIF transactivation and knockdown of KDM4C inhibits breast tumor growth and lung metastasis in mice [15]. There may also be other factors required to promote the HIFmediated upregulation of KDMs. siRNA knockout of the paired-like homeodomain pituitary gland transcription factor (PITX1) results in increased transcriptional activity of HIF and changes in JmjCKDM levels. Mudie et al. demonstrated that PITX1 and HIF- $1 \alpha$ modulate JmjC-KDM/KDM4B expression, and hence $\mathrm{H} 3 \mathrm{~K} 9 \mathrm{me} 3$ levels, in a co-operative manner, via interaction of PITX1 with HIF-1 $\beta$ at the KDM4B promoter in MDA-MB-231 and MCF-7 breast cancer cells [150].

\section{Therapeutic targeting of KDMs in cancer}

The significance of JmjC-KDM activity in cancer progression means that KDM families are now emerging as potential new targets for cancer [52] and there has been much progress in recent years toward development of small molecule inhibitors against JmjC-KDMs [151-153]. The majority of the small molecules reported to date contain a metal-chelating motif and inhibit demethylase activity via chelation of the active site $\mathrm{Fe}(\mathrm{II})$. (For a recent review see [154]).

$\mathrm{N}$-oxalylglycine (NOG), an inactive 2OG analog, inhibits all subfamilies of JmjC-KDMs with differential activity $\left(\mathrm{IC}_{50}\right.$ range of $\left.0.3-250 \mu \mathrm{M}\right)$ [155]. DMOG, a cell permeable form of NOG which is often used to inhibit HIF hydroxylases to upregulate HIF and mimic hypoxia, also targets JmjC-KDMs in cells resulting in increased global histone methylation levels [155]. 5-carboxy-8-hydroxyquinoline (IOX1), a more potent inhibitor, has been developed as an alternative generic inhibitor for $2 \mathrm{OG}$ oxygenases $[155,156]$ and was established as a chemical tool [157]. There have been some recent developments of promising KDM selective inhibitors. Both methylstat and JIB04 (pyridine-hydrazone) inhibit JmjC-KDM activity in vitro, with approximately ten-fold selectivity for JmjC-KDMs over PHD2 [158,159]. Methylstat inhibits prostate cancer cell growth, while JIB-04 inhibited both lung and prostate cell growth in vivo and in tumors $[158,159]$. Interestingly, a hybrid compound consisting of KDM1 and JmjC-KDM targeting motifs 
(4-carboxy-4'-carbomethoxy-2'-2-bipyridine) inhibited both KDM families (KDM1 and JmjC-KDMs) with high selectivity over HIF hydroxylases in vitro, and demonstrated growth arrest and apoptosis on prostate and lung cancer cells [160].

A major challenge in KDM inhibitor development is achieving selective inhibition within the JmjCKDM subfamily. One of the first promising leads developed against a JmjC-KDM subfamily is GSK-J1/ J4 [161], a cell-active compound targeting the KDM6 subfamily. While it also weakly inhibits KDM5 [162], GSK-J4 (the prodrug form) has proved to be a useful tool in epigenetic research [147,161]. Most recently, Epitherapeutics reported EPT103182 as a KDM5-targeting small molecule inhibitor with potent KDM5 inhibition in vitro and in cells [163]. EPT103182 shows an antiproliferative effect in many cancer cell lines, particularly in hematological and solid cancer cell lines, and demonstrates dose-dependent tumor growth inhibition in xenograft models [163].

\section{Cardiovascular disease \& hypoxia}

Heart failure is the common end-point of various cardiovascular conditions, including cardiac hypertrophy, myocardial infarction and myocardial ischemia $[164,165]$. As in cancer, a shift in metabolism from oxidation of fatty acids to glycolysis is seen in heart failure, which is accompanied by cardiovascular remodeling and the reactivation of fetal genes such as atrial natriuretic peptide and brain natriuretic peptide ( $A N P$ and $B N P$, respectively) [79,80] (Figure 4). This reprogramming of fetal genes has been proposed as a cardioprotective response, aimed at increasing cardiac efficiency under conditions of stress [81]. The mechanisms underlying the convergence of these diseases on a common gene expression profile are yet to be understood [166]. Cardiac hypoxia may be the result of an ischemic event, or due to systemic hypoxia or anemia [77] and is often a feature of cardiac hypertrophy [167], as well as a key contributor in the progression of hypertrophy to heart failure [168]. The contribution of epigenetic changes to cardiovascular disease is less well studied than in cancer. However, the possibility exists that focal or chronic hypoxic conditions in cardiovascular diseases may affect JmjC-KDM levels and activity and thus histone methylation status. Here we discuss evidence available to date that demonstrates associations of JmjC-KDMs with cardiovascular disease progression.

\section{JmjC-KDMs \& cardiovascular disease}

Altered histone lysine methylation patterns resulting in changes to gene expression profiles have been observed in a number of cardiovascular disease states, particularly cardiac hypertrophy and cardiomyopathy (Table 4) [169-174]. While studies to date have analyzed the downstream effect of changes to methylation status at specific gene promoter regions, genome-wide ChIP in hypertrophic cardiomyocytes revealed redistribution of methylated histone marks to both promoter and enhancer regions of specific genes associated with the disease state [175]. This suggests that changes to histone modifications are not only a result of disease, but can, in fact, drive maladaptive phenotypic changes.

Recent studies have implicated several JmjC-KDMs in a number of cardiovascular disease states. KDM4A protein levels were reported to be upregulated in hypertrophic cardiomyopathy patients [171]. Heart-specific overexpression of KDM4A in mice exacerbated cardiac hypertrophy following TAC-induced cardiac pressure overload, while heart-specific KDM4A knock-out blunted the hypertrophic response [171]. Increased levels of four and a half LIM domains 1 (FHL1, a biomechani-

\begin{tabular}{|c|c|c|c|c|}
\hline Disease state & $\begin{array}{l}\text { Changes to lysine } \\
\text { methylation status }\end{array}$ & $\begin{array}{l}\text { Gene locus and change } \\
\text { in expression level }\end{array}$ & $\begin{array}{l}\text { KDM } \\
\text { implicated? }\end{array}$ & Ref. \\
\hline \multirow[t]{2}{*}{ Heart failure } & H3K4me3 & \multirow[t]{2}{*}{ Global study } & \multirow[t]{2}{*}{-} & \multirow[t]{2}{*}{169} \\
\hline & H3K9me3 & & & \\
\hline $\begin{array}{l}\text { PTIP knock out mouse (reduced } \\
\text { global H3K4me3 model) }\end{array}$ & $\begin{array}{l}\text { H3K4me3 } \downarrow \text { (globally } \\
\text { induced) }\end{array}$ & $K C N I P 2 \downarrow$ & - & {$[170]$} \\
\hline Cardiac hypertrophy & H3K9me3 $\downarrow$ & $F H L 1 \uparrow$ & $\mathrm{KDM} 4 \mathrm{~A} \uparrow$ & {$[171]$} \\
\hline Cardiomyopathy & H3K36me3 $\downarrow$ & $D U X 4 \downarrow$ & - & {$[172]$} \\
\hline \multirow[t]{3}{*}{ Cardiomyopathy } & \multirow[t]{3}{*}{ H3K9me2/3 $\downarrow$} & $A N P \uparrow$ & $\mathrm{KDM} 3 \mathrm{~A} \uparrow$ & \multirow[t]{3}{*}[173]{} \\
\hline & & \multirow[t]{2}{*}{$B N P \uparrow$} & $\mathrm{KDM} 4 \mathrm{~A} \uparrow$ & \\
\hline & & & $\mathrm{KDM} 4 \mathrm{~B} \uparrow$ & \\
\hline
\end{tabular}


cal stress sensor implicated in the development of cardiac hypertrophy [176]) were found to be due to binding of KDM4A to the FHL1 promoter, decreasing H3K9 trimethylation and activating transcription [171]. Cardiac hypertrophy is stimulated by pressure overload, which increases myocardial oxygen demand and can lead to myocardial hypoxia [166], hence elucidating the effect of low oxygen concentrations on the JmjC-KDMs could prove to be therapeutically beneficial in this context. Importantly, increased KDM4A, KDM4B and KDM3A expression was found in heart failure patients [173]. Double knockdown experiments in neonatal rat cardiomyocytes correlated KDM3A and KDM4A expression levels with changes in expression of ANP and BNP, apparently mediated by changes to the methylation status of $\mathrm{H} 3 \mathrm{~K} 9$ in the promoter region of these genes, and it was suggested that this evidence supported a regulatory role for $\mathrm{KDM} 3 \mathrm{~A}$ and $\mathrm{KDM} 4 \mathrm{~A}$ in the reactivation of fetal genes in a disease-specific context [173].

\section{Inflammation \& JmjC-KDMs}

Atherosclerosis is a non-resolving inflammatory disease, and presents an interesting link between inflammation, hypoxia and cardiovascular disease. Atherosclerotic plaques are inherently hypoxic [177], demonstrating HIF-1 $\alpha$ stabilization [178], while atherosclerosis is itself an underlying cause of ischemic heart disease, angina, myocardial infarction and stroke.

KDM3A, KDM4B and KDM4D are upregulated in macrophages in response to hypoxia, concomitant with a global increase in levels of $\mathrm{H} 3 \mathrm{~K} 9 \mathrm{me} 2, \mathrm{H} 3 \mathrm{~K} 9 \mathrm{me} 3$ and H3K36me3, likely due to attenuation of JmjC-KDM activity [16]. Downstream reduction in expression of chemokine ligands and receptors was also observed. Interestingly, one such affected ligand, CCL2, is similarly downregulated in a murine model of atherosclerosis upon treatment with the iron chelator desferrioxamine [179], which is a generic inhibitor of the 2OG oxygenase family, including the HIF hydroxylases and the JmjC-KDMs [Unpublished data, author's laboratory].

KDM6B has been linked to inflammation in several studies. Macrophages stimulated by both lipopolysaccharides [180,181] and Serum Amyloid A (SAA) [182], an acute phase protein associated with chronic disorders including atherosclerosis [183], demonstrated upregulation of KDM6B [180-182] and KDM6Bmediated modulation of expression of inflammatory genes [181,182]. Furthermore, shRNA knock-down of KDM6B reduced uptake of oxidized low density lipoproteins by macrophages, thereby reducing the SAA-induced formation of foam cells [182], which contribute to the pathogenesis of atherosclerosis [184].

Published work has demonstrated that changes to histone lysine methylation at specific gene loci have direct consequences for the development and progression of several cardiovascular and inflammatory diseases. These changes are likely mediated, at least in part, by JmjC-KDMs, although further investigation of the specific role of JmjC-KDM activity in these disease states is required. Given the links between hypoxia and heart disease, and the hypoxic regulation of a number of these enzymes, the relationship between reduced oxygen concentration and epigenetic regulation in the context of cardiovascular disease presents an interesting avenue for further research.

\section{Conclusion \& future perspective}

Evidence is amassing that phenotypic changes in hypoxic diseases are not solely a result of the HIFdriven hypoxic response. Altered histone lysine methylation in hypoxia, resulting in changes at the transcriptional level, has been demonstrated in a variety of contexts, as described above. As with the related 2OG oxygenases, PHD and FIH, JmjC-KDMs have been shown to have different oxygen sensitivities, at least in vitro (Table $1[26]$ ), and their activity has the potential to be affected by changing oxygen concentration [20]. JmjC-KDMs may therefore regulate gene expression at specific gene loci in an oxygen concentration-dependent manner, although further evidence to support this hypothesis is needed.

Challenges remain in elucidating the relationship between oxygen availability and epigenetic regulation by the JmjC-KDMs. Potential redundancy $[107,117,185]$ and differential HIF regulation within JmjC-KDM subfamilies [14,57-58] are factors that may prove complex. It is unclear how HIF-mediated gene upregulation in hypoxia affects overall KDM activity levels since both HIF-dependent (KDM upregulation/ association) and HIF-independent (effects on catalytic activity) mechanisms (Figure $2 \mathrm{C}-\mathrm{E}$ ) may be at play. Several JmjC-KDM sub-families are known to have demethylase-independent roles in gene regulation [186-188]. In the context of epigenetic changes and oxygen availability, it is also important to consider DNA methylation patterns which are altered in hypoxia $[189,190]$. While it is beyond the scope of this review, DNA demethylation mediated by Ten-eleven translocation methylcytosine dioxygenases (TETs, including TET1-3), another family of 2OG oxygenases, may also be key players in epigenetic regulation under hypoxic conditions.

In order to address these questions, development of specific and potent chemical probes for these enzymes will be essential. Indeed, some promising chemical probes for this enzyme family have already been identified [153,154]. There is also a need to develop more precise and reliable methods for measurement of oxygen 
concentration in cells and tissues, such as fiber-optic, small molecule or cell-permeable nanoparticle probes.

A large body of evidence indicates that the JmjCKDMs have key roles in gene regulation and that misregulation of the JmjC-KDMs is a pathological feature in hypoxic disease states. Reduced activity of at least some of the JmjC-KDMs in hypoxia may be an influencing factor. Further biochemical, kinetic and physiological characterization is necessary to validate this proposal, and will confirm the importance of the JmjC-KDMs as therapeutic targets for the treatment of diseases of the maladaptive hypoxic response.

\section{Acknowledgements}

The authors thank CJ Schofield for helpful discussions, and S Bhattacharya, E Hammond and S Lakhal-Littleton for critical reading.
Financial \& competing interests disclosure

The authors acknowledge support from the British Heart Foundation Centre of Research Excellence, Oxford (RE/08/004/23915) and from Cancer Research UK (C8717/ A18245). E Flashman and A Kawamura are supported by Royal Society Dorothy Hodgkin Fellowships. The authors have no other relevant affiliations or financial involvement with any organization or entity with a financial interest in or financial conflict with the subject matter or materials discussed in the manuscript apart from those disclosed.

No writing assistance was utilized in the production of this manuscript.

\section{Open Access}

This work is licensed under the Creative Commons AttributionNonCommercial 4.0 Unported License. To view a copy of this license, visit http://creativecommons.org/licenses/by-nc-nd/4.0/

\section{Executive summary}

\section{Hypoxia, HIF \& the HIF hydroxylases}

- HIF mediates the hypoxic response and HIF levels are regulated by the HIF hydroxylases, oxygen-dependent enzymes which are members of the 20G-dependent oxygenase family.

\section{Histone demethylation by the JmjC-KDMs}

- JmjC-KDMs are $20 \mathrm{G}$ oxygenases, which play key roles in epigenetic regulation and act by modulating dynamic histone lysine methylation states.

- Levels of some JmjC-KDMs are upregulated in hypoxia, and kinetic studies suggest their activity could be sensitive to decreased oxygen availability, with potentially important consequences for gene regulation in hypoxia.

Hypoxia, development \& the JmjC-KDMs

- Hypoxia is an essential regulator of normal development, while various JmjC-KDMs are critical to different types of development.

- Understanding how the JmjC-KDMs contribute to gene regulation in development may prove useful in understanding how aberrant function, especially in hypoxia, may contribute to disease states.

Hypoxia, cancer \& the JmjC-KDMs

- Hypoxic conditions commonly occur within solid tumors and cause a HIF-mediated hypoxic transcriptional response.

- Hypoxia-induced epigenetic changes may contribute to altered gene expression in cancer.

- Many JmjC-KDMs have been implicated in cancer, and some have been identified as oncogenes.

- Inhibitors targeting JmjC-KDMs are being developed as cancer therapeutics.

Hypoxia, cardiovascular disease \& the JmjC-KDMs

- Altered gene expression and histone methylation patterns have been identified in several cardiovascular disease states.

- Data are emerging that indicate JmjC-KDMs may contribute to these conditions in a pathological manner.

Conclusion

- Hypoxia may be a contributing factor to the aberrant function of various JmjC-KDMs that have been implicated in hypoxic disease states.

- There is a need to further characterize the effect of hypoxia on the activity and expression of JmjC-KDMs.

- To this end, further biochemical and physiological study, and the development of potent and selective inhibitors will be essential.

Unanswered questions

- What are the oxygen sensitivities of JmjC-KDMs? Do they vary between different JmjC-KDMs families and isoforms? Can the JmjC-KDMs act as oxygen sensors?

- Is gene expression regulated by JmjC-KDMs in an oxygen dependent manner?

- Are the JmjC-KDMs overexpressed to compensate for loss of enzyme activity at low oxygen concentrations?

- Does both HIF-dependent and HIF-independent transcriptional regulation by JmjC-KDMs occur under different oxygen stress?

- What is the actual, absolute concentration of oxygen experienced by cells exposed to a hypoxic environment, or by cells within a physiologically hypoxic microenvironment? 


\section{References}

Papers of special note have been highlighted as:

- of interest; $\bullet \bullet$ of considerable interest

- Carreau A, El Hafny-Rahbi B, Matejuk A, Grillon C, Kieda C. Why is the partial oxygen pressure of human tissues a crucial parameter? Small molecules and hypoxia. J. Cell. Mol. Med. 15(6), 1239-1253 (2011).

- Harvey AJ, Kind KL, Thompson JG. REDOX regulation of early embryo development. Reproduction 123(4), 479-486 (2002).

3 Fischer B, Bavister BD. Oxygen tension in the oviduct and uterus of rhesus monkeys, hamsters and rabbits. J. Reprod. Fertil. 99(2), 673-679 (1993).

4 Bertout JA, Patel SA, Simon MC. The impact of O2 availability on human cancer. Nat. Rev. Cancer 8(12), 967-975 (2008).

- Chen EY, Fujinaga M, Giaccia AJ. Hypoxic microenvironment within an embryo induces apoptosis and is essential for proper morphological development. Teratology 60(4), 215-225 (1999).

6 Kaelin WG, Ratcliffe PJ. Oxygen sensing by metazoans: the central role of the HIF hydroxylase pathway. Mol. Cell 30(4), 393-402 (2008).

7 Myllyharju J. Prolyl 4-hydroxylases, master regulators of the hypoxia response. Acta Physiol. (Oxf.) 208(2), 148-165 (2013).

8 Semenza GL. Oxygen sensing, hypoxia-inducible factors, and disease pathophysiology. Annu. Rev. Pathol. 9, 47-71 (2014).

- Chowdhury R, Hardy A, Schofield CJ. The human oxygen sensing machinery and its manipulation. Chem. Soc. Rev. 37(7), 1308-1319 (2008).

10 Loboda A, Jozkowicz A, Dulak J. HIF-1 and HIF-2 transcription factors-similar but not identical. Mol. Cells 29(5), 435-442 (2010).

11 Semenza GL. Hypoxia-inducible factor 1: master regulator of O2 homeostasis. Curr. Opin. Genet. Dev. 8(5), 588-594 (1998).

$\nabla_{12}$ Kouzarides T. Chromatin modifications and their function. Cell 128(4), 693-705 (2007).

13 Krieg AJ, Rankin EB, Chan D, Razorenova O, Fernandez S, Giaccia AJ. Regulation of the histone demethylase JMJD1A by hypoxia-inducible factor 1 alpha enhances hypoxic gene expression and tumor growth. Mol. Cell Biol. 30(1), 344-353 (2010).

14 Xia X, Lemieux ME, Li W et al. Integrative analysis of HIF binding and transactivation reveals its role in maintaining histone methylation homeostasis. Proc. Natl Acad. Sci. USA 106(11), 4260-4265 (2009).

15 Luo W, Chang R, Zhong J, Pandey A, Semenza GL. Histone demethylase JMJD2C is a coactivator for hypoxia-inducible factor 1 that is required for breast cancer progression. Proc. Natl Acad. Sci. USA 109(49), E3367-E3376 (2012).

-• Demonstrates a key role for recruitment of KDM4C by HIF- $1 \alpha$ to hypoxia response elements in enhancing HIFmediated transactivation of specific target genes.
16 Tausendschon M, Dehne N, Brune B. Hypoxia causes epigenetic gene regulation in macrophages by attenuating Jumonji histone demethylase activity. Cytokine 53(2), 256-262 (2011).

- Implicates loss of JmjC-KDM activity in a global increase in histone lysine methylation induced under hypoxic conditions in macrophages.

Hausinger RP. Fe(II)/ $\alpha$-ketoglutarate-dependent hydroxylases and related enzymes. Crit. Rev. Biochem. Mol. Biol. 39(1), 21-68 (2008).

18 McDonough MA, Loenarz C, Chowdhury R, Clifton IJ, Schofield CJ. Structural studies on human 2-oxoglutarate dependent oxygenases. Curr. Opin. Struct. Biol. 20(6), 659-672 (2010).

19 Clifton IJ, McDonough MA, Ehrismann D, Kershaw NJ, Granatino N, Schofield CJ. Structural studies on 2-oxoglutarate oxygenases and related double-stranded betahelix fold proteins. J. Inorg. Biochem. 100(4), 644-669 (2006).

-20 Sanchez-Fernandez EM, Tarhonskaya H, Al-Qahtani Ket al. Investigations on the oxygen dependence of a 2-oxoglutarate histone demethylase. Biochem. J. 449(2), 491-496 (2013).

-• Establishes that KDM4E demonstrates a graded response to oxygen over a physiologically relevant range of oxygen concentrations in vitro.

-21 Chan DA, Sutphin PD, Yen S-E, Giaccia AJ. Coordinate regulation of the oxygen-dependent degradation domains of hypoxia-inducible factor 1 alpha. Mol. Cell Biol. 25(15), 6415-6426 (2005).

22 Tian Y-M, Yeoh KK, Lee MK et al. Differential sensitivity of hypoxia inducible factor hydroxylation sites to hypoxia and hydroxylase inhibitors. J. Biol. Chem. 286(15), 13041-13051 (2011).

23 Hirsilä M, Koivunen P, Günzler V, Kivirikko KI, Myllyharju J. Characterization of the human prolyl 4-hydroxylases that modify the hypoxia-inducible factor. J. Biol. Chem. 278(33), 30772-30780 (2003).

24 Ehrismann D, Flashman E, Genn DN et al. Studies on the activity of the hypoxia-inducible-factor hydroxylases using an oxygen consumption assay. Biochem. J. 401(1), 227-234 (2007).

-25 Koivunen P, Hirsilä M, Günzler V, Kivirikko KI, Myllyharju J. Catalytic properties of the asparaginyl hydroxylase (FIH) in the oxygen sensing pathway are distinct from those of its prolyl 4-hydroxylases. J. Biol. Chem. 279(11), 9899-9904 (2004).

26 Cascella B, Mirica LM. Kinetic analysis of iron-dependent histone demethylases: $\alpha$-ketoglutarate substrate inhibition and potential relevance to the regulation of histone demethylation in cancer cells. Biochemistry 51(44), 8699-8701 (2012).

- Demonstrates differential in vitro oxygen sensitivity of KDM4 subfamily members.

-27 Tarhonskaya H, Chowdhury R, Leung IKH et al. Investigating the contribution of the active site environment to the slow reaction of hypoxia-inducible factor prolyl hydroxylase domain 2 with oxygen. Biochem. J. 463(3), 363-372 (2014). 
28 Dao JH, Kurzeja RJM, Morachis JM et al. Kinetic characterization and identification of a novel inhibitor of hypoxia-inducible factor prolyl hydroxylase 2 using a timeresolved fluorescence resonance energy transfer-based assay technology. Anal. Biochem. 384(2), 213-223 (2009).

-29 Flashman E, Hoffart LM, Hamed RB, Bollinger JM Jr, Krebs C, Schofield CJ. Evidence for the slow reaction of hypoxiainducible factor prolyl hydroxylase 2 with oxygen. FEBS J. 277(19), 4089-4099 (2010).

30 Berra E, Benizri E, Ginouvès A, Volmat V, Roux D, Pouysségur J. HIF prolyl-hydroxylase 2 is the key oxygen sensor setting low steady-state levels of HIF-1alpha in normoxia. EMBO J. 22 (16), 4082-4090 (2003).

- 31 Ozolins, TRS, Fisher TS, Nadeau DM et al. Defects in embryonic development of EGLN1/PHD2 knockdown transgenic mice are associated with induction of Igfbp in the placenta. Biochem. Biophys. Res. Commun. 390(3), 372-376 (2009).

- 32 Wilkins SE, Hyvärinen J, Chicher J et al. Differences in hydroxylation and binding of Notch and HIF-1alpha demonstrate substrate selectivity for factor inhibiting HIF-1 (FIH-1). Int. J. Biochem. Cell Biol. 41(7), 1563-1571 (2009).

33 Cockman ME, Lancaster DE, Stolze IP et al. Posttranslational hydroxylation of ankyrin repeats in IkappaB proteins by the hypoxia-inducible factor (HIF) asparaginyl hydroxylase, factor inhibiting HIF (FIH). Proc. Natl Acad. Sci. USA 103(40), 14767-14772 (2006).

- 34 Coleman ML, McDonough MA, Hewitson KS et al. Asparaginyl hydroxylation of the Notch ankyrin repeat domain by factor inhibiting hypoxia-inducible factor. J. Biol. Chem. 282(33), 24027-24038 (2007).

- 35 Kelly L, McDonough MA, Coleman ML, Ratcliffe PJ, Schofield CJ. Asparagine beta-hydroxylation stabilizes the ankyrin repeat domain fold. Mol. Biosyst. 5(1), 52-58 (2009).

- 36 Zhang N, Fu Z, Linke S et al. The asparaginyl hydroxylase factor inhibiting HIF-1alpha is an essential regulator of metabolism. Cell Metab. 11(5), 364-378 (2010).

- 37 Ryle MJ, Padmakumar R, Hausinger RP. Stoppedflow kinetic analysis of Escherichia coli taurine/alphaketoglutarate dioxygenase: interactions with alphaketoglutarate, taurine, and oxygen. Biochemistry 38(46), 15278-15286 (1999).

- 38 Hoffart LM, Barr EW, Guyer RB, Bollinger JM, Krebs C. Direct spectroscopic detection of a C-H-cleaving high-spin $\mathrm{Fe}(\mathrm{IV})$ complex in a prolyl-4-hydroxylase. Proc. Natl Acad. Sci. USA 103(40), 14738-14743 (2006).

-39 Tan M, Luo H, Lee S et al. Identification of 67 histone marks and histone lysine crotonylation as a new type of histone modification. Cell 146(6), 1016-1028 (2011).

40 Strahl BD, Allis CD. The language of covalent histone modifications. Nature 403(6765), 41-45 (2000).

-41 Barski A, Cuddapah S, Cui K et al. High-resolution profiling of histone methylations in the human genome. Cell 129(4), 823-837 (2007).

- 42 Kooistra SM, Helin K. Molecular mechanisms and potential functions of histone demethylases. Nat. Rev. Mol. Cell Biol. 13(5), 297-311 (2012).
43 Bernstein BE, Mikkelsen TS, Xie X et al. A bivalent chromatin structure marks key developmental genes in embryonic stem cells. Cell 125(2), 315-326 (2006).

44 Rea S, Eisenhaber F, O'Carroll D et al. Regulation of chromatin structure by site-specific histone $\mathrm{H} 3$ methyltransferases. Nature 406(6796), 593-599 (2000).

45 Dillon SC, Zhang X, Trievel RC, Cheng X. The SET-domain protein superfamily: protein lysine methyltransferases. Genome Biol. 6(8), 227 (2005).

- 46 Feng Q, Wang H, Ng HH et al. Methylation of H3-lysine 79 is mediated by a new family of HMTases without a SET domain. Curr. Biol. 12(12), 1052-1058 (2002).

- 47 Ng SS, Kavanagh KL, McDonough MA et al. Crystal structures of histone demethylase JMJD2A reveal basis for substrate specificity. Nature 448(7149), 87-91 (2007).

48 Chen Z, Zang J, Whetstine J et al. Structural insights into histone demethylation by JMJD2 family members. Cell 125(4), 691-702 (2006).

\49 Couture J-F, Collazo E, Ortiz-Tello PA, Brunzelle JS, Trievel RC. Specificity and mechanism of JMJD2A, a trimethyllysine-specific histone demethylase. Nat. Struct. Mol. Biol. 14(8), 689-695 (2007).

50 Aik W, McDonough MA, Thalhammer A, Chowdhury R, Schofield CJ. Role of the jelly-roll fold in substrate binding by 2-oxoglutarate oxygenases. Curr. Opin. Struct. Biol. 22(6), 691-700 (2012).

-51 Klose RJ, Kallin EM, Zhang Y. JmjC-domain-containing proteins and histone demethylation. Nat. Rev. Genet. 7(9), 715-727 (2006).

-52 Højfeldt JW, Agger K, Helin K. Histone lysine demethylases as targets for anticancer therapy. Nat. Rev. Drug Discov. 12(12), 917-930 (2013).

53 Williams ST, Walport LJ, Hopkinson RJ et al. Studies on the catalytic domains of multiple JmjC oxygenases using peptide substrates. Epigenetics 9(12), 1596-1603 (2015).

- 54 Horton JR, Upadhyay AK, Qi HH, Zhang X, Shi Y, Cheng $\mathrm{X}$. Enzymatic and structural insights for substrate specificity of a family of jumonji histone lysine demethylases. Nat. Struct. Mol. Biol. 17(1), 38-43 (2010).

-55 Mosammaparast N, Shi Y. Reversal of histone methylation: biochemical and molecular mechanisms of histone demethylases. Annu. Rev. Biochem. 79, 155-179 (2010).

56 Lee H-Y, Choi K, Oh H, Park, Y-K, Park H. HIF-1-dependent induction of Jumonji domain-containing protein (JMJD) 3 under hypoxic conditions. Mol. Cells 37(1), 43-50 (2014).

- 57 Beyer S, Kristensen MM, Jensen KS, Johansen JV, Staller P. The histone demethylases JMJD1A and JMJD2B are transcriptional targets of hypoxia-inducible factor HIF. J. Biol. Chem. 283(52), 36542-36552 (2008).

-• Demonstrates HIF-mediated upregulation of KDM3A and $4 \mathrm{~B}$, while showing differential sensitivity toward hypoxic environments between these enzymes in a cellular context.

-58 Pollard PJ, Loenarz C, Mole DR et al. Regulation of Jumonjidomain-containing histone demethylases by hypoxiainducible factor (HIF)-1alpha. Biochem. J. 416(3), 387-394 (2008). 
- Establishes HIF-1 $\alpha$-mediated upregulation of a number of JmjC-KDMs.

-59 Wellmann S, Bettkober M, Zelmer A et al. Hypoxia upregulates the histone demethylase JMJD1A via HIF-1. Biochem. Biophys. Res. Commun. 372(4), 892-897 (2008).

60 Niu X, Zhang T, Liao L et al. The von Hippel-Lindau tumor suppressor protein regulates gene expression and tumor growth through histone demethylase JARID1C. Oncogene 31(6), 776-786 (2012).

61 Yang J, Ledaki I, Turley H et al. Role of hypoxia-inducible factors in epigenetic regulation via histone demethylases. Ann. NY Acad. Sci. 1177, 185-197 (2009).

62 Shmakova A, Batie M, Druker J, Rocha S. Chromatin and oxygen sensing in the context of JmjC histone demethylases. Biochem. J. 462(3), 385-395 (2014).

63 Lee HY, Yang EG, Park H. Hypoxia enhances the expression of prostate-specific antigen by modifying the quantity and catalytic activity of Jumonji $\mathrm{C}$ domain-containing histone demethylases. Carcinogenesis 34(12), 2706-2715 (2013).

-64 Costa M, Davidson TL, Chen H et al. Nickel carcinogenesis: epigenetics and hypoxia signaling. Mutat. Res. 592(1-2), 79-88 (2005).

-65 Islam KN, Mendelson CR. Permissive effects of oxygen on cyclic AMP and interleukin-1 stimulation of surfactant protein A gene expression are mediated by epigenetic mechanisms. Mol. Cell Biol. 26(8), 2901-2912 (2006).

-66 Chen H, Yan Y, Davidson TL, Shinkai Y, Costa M. Hypoxic stress induces dimethylated histone $\mathrm{H} 3$ lysine 9 through histone methyltransferase G9a in mammalian cells. Cancer Res. 66(18), 9009-9016 (2006).

67 Johnson AB, Denko N, Barton MC. Hypoxia induces a novel signature of chromatin modifications and global repression of transcription. Mutat. Res. 640(1-2), 174-179 (2008).

-68 Zhou X, Sun H, Chen H et al. Hypoxia induces trimethylated $\mathrm{H} 3$ lysine 4 by inhibition of JARID1A demethylase. Cancer Res. 70 (10), 4214-4221 (2010).

-69 Osumek JE, Revesz A, Morton JS, Davidge ST, Hardy DB. Enhanced trimethylation of histone h3 mediates impaired expression of hepatic glucose 6-phosphatase expression in offspring from rat dams exposed to hypoxia during pregnancy. Reprod. Sci. 21(1), 112-121 (2014).

70 Perez-Perri JI, Acevedo JM, Wappner P. Epigenetics: new questions on the response to hypoxia. Int. J. Mol. Sci. 12(7), 4705-4721 (2011).

71 Melvin A, Rocha S. Chromatin as an oxygen sensor and active player in the hypoxia response. Cell. Signal. 24(1), 35-43 (2012).

72 Guo X, Tian Z, Wang X et al. Regulation of histone demethylase KDM6B by hypoxia-inducible factor-2 $\alpha$. Acta Biochim. Biophys. Sin. (Shanghai) 47(2), 106-113 (2014).

73 Dunwoodie SL. The role of hypoxia in development of the Mammalian embryo. Dev. Cell 17(6), 755-773 (2009).

74 Ufer C, Wang CC. The roles of glutathione peroxidases during embryo development. Front. Mol. Neurosci. 4, 12 (2011).
75 Jauniaux E, Gulbis B, Burton GJ. The human first trimester gestational sac limits rather than facilitates oxygen transfer to the foetus - a review. Placenta 24(Suppl. A), S86-S93 (2003).

76 Hutter D, Kingdom J, Jaeggi E. Causes and mechanisms of intrauterine hypoxia and its impact on the fetal cardiovascular system: a review. Int. J. Pediatr. 401323 (2010) (2010).

77 Ostadal B, Ostadalova I, Dhalla NS. Development of cardiac sensitivity to oxygen deficiency: comparative and ontogenetic aspects. Physiol. Rev. 79(3), 635-659 (1999).

78 Puente BN, Kimura W, Muralidhar SA et al. The oxygen-rich postnatal environment induces cardiomyocyte cell-cycle arrest through DNA damage response. Cell 157(3), 565-579 (2014).

79 Taegtmeyer H, Sen S, Vela D. Return to the fetal gene program: a suggested metabolic link to gene expression in the heart. Ann. NY Acad. Sci. 1188, 191-198 (2010).

-80 Razeghi P, Young ME, Alcorn JL, Moravec CS, Frazier OH, Taegtmeyer H. Metabolic gene expression in fetal and failing human heart. Circulation 104(24), 2923-2931 (2001).

81 Rajabi M, Kassiotis C, Razeghi P, Taegtmeyer H. Return to the fetal gene program protects the stressed heart: a strong hypothesis. Heart Fail. Rev. 12(3-4), 331-343 (2007).

82 Patterson AJ, Zhang L. Hypoxia and fetal heart development. Curr. Mol. Med. 10 (7), 653-666 (2010).

83 Balasubramaniam V, Mervis CF, Maxey AM, Markham NE, Abman SH. Hyperoxia reduces bone marrow, circulating, and lung endothelial progenitor cells in the developing lung: implications for the pathogenesis of bronchopulmonary dysplasia. Am. J. Physiol. Lung Cell. Mol. Physiol. 292(5), L1073-L1084 (2007).

-84 Mohyeldin A, Garzón-Muvdi T, Quiñones-Hinojosa A. Oxygen in stem cell biology: a critical component of the stem cell niche. Cell Stem Cell 7(2), 150-161 (2010).

85 Guo N, Li Y, Ai J, Gu L, Chen W, Liu Q. Two different concentrations of oxygen for culturing precompaction stage embryos on human embryo development competence: a prospective randomized sibling-oocyte study. Int. J. Clin. Exp. Pathol. 7(9), 6191-6198 (2014).

86 Vastenhouw NL, Schier AF. Bivalent histone modifications in early embryogenesis. Curr. Opin. Cell Biol. 24(3), 374-386 (2012).

87 Denissov S, Hofemeister H, Marks H et al. Mll2 is required for $\mathrm{H} 3 \mathrm{~K} 4$ trimethylation on bivalent promoters in embryonic stem cells, whereas Mll1 is redundant. Development 141(3), 526-537 (2014).

88 Alder O, Lavial F, Helness A et al. Ring1B and Suv39h1 delineate distinct chromatin states at bivalent genes during early mouse lineage commitment. Development 137(15), 2483-2492 (2010).

89 Rugg-Gunn PJ, Cox BJ, Ralston A, Rossant J. Distinct histone modifications in stem cell lines and tissue lineages from the early mouse embryo. Proc. Natl Acad. Sci. USA 107(24), 10783-10790 (2010).

-90 Vastenhouw NL, Zhang Y, Woods IG et al. Chromatin signature of embryonic pluripotency is established during genome activation. Nature 464(7290), 922-926 (2010). 
-91 Dahl JA, Reiner AH, Klungland A, Wakayama T, Collas P. Histone $\mathrm{H} 3$ lysine 27 methylation asymmetry on developmentally-regulated promoters distinguish the first two lineages in mouse preimplantation embryos. PLoS ONE 5(2), e9150 (2010).

\$2 Leschik J, Caron L, Yang H, Cowan C, Pucéat M. A view of bivalent epigenetic marks in two human embryonic stem cell lines reveals a different cardiogenic potential. Stem Cells Dev. 24(3), 384-392 (2014).

93 Voigt P, Tee W-W, Reinberg D. A double take on bivalent promoters. Genes Dev. 27(12), 1318-1338 (2013).

94 Soshnikova N, Duboule D. Epigenetic regulation of Hox gene activation: the waltz of methyls. Bioessays 30 (3), 199-202 (2008).

\$5 Zheng L-W, Zhang B-P, Xu R-S, Xu X, Ye L, Zhou X-D. Bivalent histone modifications during tooth development. Int. J. Oral Sci. 6(4), 205-211 (2014).

-96 Lee MG, Villa R, Trojer P et al. Demethylation of H3K27 regulates polycomb recruitment and $\mathrm{H} 2 \mathrm{~A}$ ubiquitination. Science 318(5849), 447-450 (2007).

-97 Agger K, Cloos PAC, Christensen J et al. UTX and JMJD3 are histone $\mathrm{H} 3 \mathrm{~K} 27$ demethylases involved in HOX gene regulation and development. Nature 449(7163), 731-734 (2007).

\$8 Nottke A, Colaiacovo MP, Shi Y, Colaiácovo MP. Developmental roles of the histone lysine demethylases. Development 136(6), 879-889 (2009).

99 Pedersen MT, Helin K. Histone demethylases in development and disease. Trends Cell Biol. 20(11), 662-671 (2010).

100 Dambacher S, Hahn M, Schotta G. Epigenetic regulation of development by histone lysine methylation. Heredity (Edinb). 105(1), 24-37 (2010).

101 Wang J, Zhang M, Zhang Y et al. The histone demethylase JMJD2C is stage-specifically expressed in preimplantation mouse embryos and is required for embryonic development. Biol. Reprod. 82(1), 105-111 (2010).

102 Pagé-Larivière F, Sirard M-A. Spatiotemporal expression of DNA demethylation enzymes and histone demethylases in bovine embryos. Cell. Reprogram. 16(1), 40-53 (2014).

103 Banka S, Lederer D, Benoit V et al. Novel KDM6A (UTX) mutations and a clinical and molecular review of the X-linked Kabuki syndrome (KS2). Clin. Genet. 87(3), 252-258 (2014).

104 Abidi FE, Miano MG, Murray JC, Schwartz CE. A novel mutation in the PHF8 gene is associated with X-linked mental retardation with cleft lip/cleft palate. Clin. Genet. 72(1), 19-22 (2007).

- 105 Ounap K, Puusepp-Benazzouz H, Peters M et al. A novel c. $2 \mathrm{~T}>\mathrm{C}$ mutation of the KDM5C/JARID1C gene in one large family with X-linked intellectual disability. Eur. J. Med. Genet. 55(3), 178-184 (2012).

106 Fukuda T, Tokunaga A, Sakamoto R, Yoshida N. Fbxl10/ $\mathrm{Kdm} 2 \mathrm{~b}$ deficiency accelerates neural progenitor cell death and leads to exencephaly. Mol. Cell Neurosci. 46(3), 614-624 (2011).

107 Kawakami E, Tokunaga A, Ozawa M, Sakamoto R, Yoshida $\mathrm{N}$. The histone demethylase $\mathrm{fbx} 111 / \mathrm{kdm} 2$ a plays an essential role in embryonic development by repressing cell-cycle regulators. Mech. Dev. 135, 31-42 (2014).

108 Testoni S, Bartolone E, Rossi M et al. KDM2B is implicated in bovine lethal multi-organic developmental dysplasia. PLoS ONE 7(9), e45634 (2012).

109 Murgiano L, Drögemüller C, Sbarra F, Bolcato M, Gentile A. Prevalence of paunch calf syndrome carriers in Italian Romagnola cattle. Vet. J. 200 (3), 459-461 (2014).

- 110 Kuroki S, Matoba S, Akiyoshi M et al. Epigenetic regulation of mouse sex determination by the histone demethylase Jmjd1a. Science 341(6150), 1106-1109 (2013).

- 111 Herzog M, Josseaux E, Dedeurwaerder S, Calonne E, Volkmar M, Fuks F. The histone demethylase Kdm3a is essential to progression through differentiation. Nucleic Acids Res. 40 (15), 7219-7232 (2012).

- 112 Tsurumi A, Dutta P, Dutta P et al. Drosophila Kdm4 demethylases in histone $\mathrm{H} 3$ lysine 9 demethylation and ecdysteroid signaling. Sci. Rep. 3, 2894 (2013).

- 113 Schmitz SU, Albert M, Malatesta M et al. Jarid1b targets genes regulating development and is involved in neural differentiation. EMBO J. 30(22), 4586-4600 (2011).

- 114 Albert M, Schmitz SU, Kooistra SM et al. The histone demethylase Jarid $1 \mathrm{~b}$ ensures faithful mouse development by protecting developmental genes from aberrant $\mathrm{H} 3 \mathrm{~K} 4 \mathrm{me} 3$. PLoS Genet. 9(4), e1003461 (2013).

115 Poeta L, Fusco F, Drongitis D et al. A regulatory path associated with X-linked intellectual disability and epilepsy links KDM5C to the polyalanine expansions in ARX. Am. J. Hum. Genet. 92(1), 114-125 (2013).

116 Iwase S, Lan F, Bayliss P et al. The X-linked mental retardation gene SMCX/JARID1C defines a family of histone H3 lysine 4 demethylases. Cell 128(6), 1077-1088 (2007).

- 117 Welstead GG, Creyghton MP, Bilodeau S et al. X-linked H3K27me3 demethylase Utx is required for embryonic development in a sex-specific manner. Proc. Natl Acad. Sci. USA 109(32), 13004-13009 (2012).

- 118 Burgold T, Spreafico F, De Santa F et al. The histone H3 lysine 27-specific demethylase Jmjd3 is required for neural commitment. PLoS ONE 3(8), e3034 (2008).

119 Jepsen K, Solum D, Zhou T et al. SMRT-mediated repression of an $\mathrm{H} 3 \mathrm{~K} 27$ demethylase in progression from neural stem cell to neuron. Nature 450 (7168), 415-419 (2007).

120 Estarás C, Akizu N, García A, Beltrán S, de la Cruz X, Martínez-Balbás MA. Genome-wide analysis reveals that Smad3 and JMJD3 HDM co-activate the neural developmental program. Development 139(15), 2681-2691 (2012).

121 Shahhoseini M, Taghizadeh Z, Hatami M, Baharvand H. Retinoic acid dependent histone 3 demethylation of the clustered HOX genes during neural differentiation of human embryonic stem cells. Biochem. Cell Biol. 91(2), 116-122 (2013).

122 Ohtani K, Zhao C, Dobreva G et al. Jmjd3 controls mesodermal and cardiovascular differentiation of embryonic stem cells. Circ. Res. 113(7), 856-862 (2013). 
123 Lee S, Lee JW, Lee S-K. UTX, a histone H3-Lysine 27 demethylase, acts as a critical switch to activate the cardiac developmental program. Dev. Cell 22(1), 25-37 (2012).

124 Tsukada Y, Ishitani T, Nakayama KI. KDM7 is a dual demethylase for histone H3 Lys 9 and Lys 27 and functions in brain development. Genes Dev. 24(5), 432-437 (2010).

125 Loenarz C, Ge W, Coleman ML et al. PHF8, a gene associated with cleft lip/palate and mental retardation, encodes for an N -dimethyl lysine demethylase. Hum. Mol. Genet. 19(2), 217-222 (2009).

126 Qi HH, Sarkissian M, Hu G-Q et al. Histone H4K20/H3K9 demethylase PHF8 regulates zebrafish brain and craniofacial development. Nature 466(7305), 503-507 (2010).

127 Kleine-Kohlbrecher D, Christensen J, Vandamme J et al. A functional link between the histone demethylase PHF8 and the transcription factor ZNF711 in X-linked mental retardation. Mol. Cell 38(2), 165-178 (2010).

128 Huang C, Xiang Y, Wang Y et al. Dual-specificity histone demethylase KIAA1718 (KDM7A) regulates neural differentiation through FGF4. Cell Res. 20(2), 154-165 (2010).

129 WARBURG O. On the origin of cancer cells. Science 123(3191), 309-314 (1956).

130 Dawson MA, Kouzarides T. Cancer epigenetics: from mechanism to therapy. Cell 150(1), 12-27 (2012).

131 Greer EL, Shi Y. Histone methylation: a dynamic mark in health, disease and inheritance. Nat. Rev. Genet. 13(5), 343-357 (2012).

132 Cho H-S, Toyokawa G, Daigo Y et al. The JmjC domaincontaining histone demethylase KDM3A is a positive regulator of the G1/S transition in cancer cells via transcriptional regulation of the HOXA1 gene. Int. J. Cancer 131(3), E179-E189 (2012).

133 Yamada D, Kobayashi S, Yamamoto H et al. Role of the hypoxia-related gene, JMJD1A, in hepatocellular carcinoma: clinical impact on recurrence after hepatic resection. Ann. Surg. Oncol. 19(Suppl. 3), S355-S364 (2012).

134 Park SJ, Kim JG, Son TG et al. The histone demethylase JMJD1A regulates adrenomedullin-mediated cell proliferation in hepatocellular carcinoma under hypoxia. Biochem. Biophys. Res. Commun. 434(4), 722-727 (2013).

135 Uemura M, Yamamoto H, Takemasa I et al. Jumonji domain containing $1 \mathrm{~A}$ is a novel prognostic marker for colorectal cancer: in vivo identification from hypoxic tumor cells. Clin. Cancer Res. 16(18), 4636-4646 (2010).

136 Cloos PAC, Christensen J, Agger K et al. The putative oncogene GASC1 demethylates tri- and dimethylated lysine 9 on histone H3. Nature 442(7100), 307-311 (2006).

137 Black JC, Allen A, Van Rechem C et al. Conserved antagonism between JMJD2A/KDM4A and HP1 $\gamma$ during cell cycle progression. Mol. Cell 40(5), 736-748 (2010).

138 Berry WL, Janknecht R. KDM4/JMJD2 histone demethylases: epigenetic regulators in cancer cells. Cancer Res. 73(10), 2936-2942 (2013).

139 Wissmann M, Yin N, Müller JM et al. Cooperative demethylation by JMJD2C and LSD1 promotes androgen receptor-dependent gene expression. Nat. Cell Biol. 9(3), 347-353 (2007).
140 Liu G, Bollig-Fischer A, Kreike B et al. Genomic amplification and oncogenic properties of the GASC1 histone demethylase gene in breast cancer. Oncogene 28(50), 4491-4500 (2009).

141 Metzger E, Wissmann M, Yin N et al. LSD1 demethylates repressive histone marks to promote androgen-receptordependent transcription. Nature 437(7057), 436-439 (2005).

142 Yamane K, Toumazou C, Tsukada Y et al. JHDM2A, a JmjC-containing H3K9 demethylase, facilitates transcription activation by androgen receptor. Cell 125(3), 483-495 (2006).

143 Yamane K, Tateishi K, Klose RJ et al. PLU-1 is an H3K4 demethylase involved in transcriptional repression and breast cancer cell proliferation. Mol. Cell 25(6), 801-812 (2007).

144 Roesch A, Fukunaga-Kalabis M, Schmidt EC et al. A temporarily distinct subpopulation of slow-cycling melanoma cells is required for continuous tumor growth. Cell 141(4), 583-594 (2010).

145 Xiang Y, Zhu Z, Han G et al. JARID1B is a histone H3 lysine 4 demethylase up-regulated in prostate cancer. Proc. Natl Acad. Sci. USA 104(49), 19226-19231 (2007).

146 Blair LP, Cao J, Zou MR, Sayegh J, Yan Q. Epigenetic regulation by lysine demethylase 5 (KDM5) enzymes in cancer. Cancers (Basel) 3(1), 1383-1404 (2011).

147 Ntziachristos P, Tsirigos A, Welstead GG et al. Contrasting roles of histone 3 lysine 27 demethylases in acute lymphoblastic leukaemia. Nature 514(7523), 513-517 (2014).

148 Shen Y, Guo X, Wang Y et al. Expression and significance of histone H3K27 demethylases in renal cell carcinoma. BMC Cancer 12, 470 (2012).

149 Ueda J, Ho JC, Lee KL et al. The hypoxia-inducible epigenetic regulators Jmjd1a and G9a provide a mechanistic link between angiogenesis and tumor growth. Mol. Cell Biol. 34(19), 3702-3720 (2014).

150 Mudie S, Bandarra D, Batie M et al. PITX1, a specificity determinant in the HIF-1 $\alpha$-mediated transcriptional response to hypoxia. Cell Cycle 13(24), 3878-3891 (2014).

151 Lohse B, Kristensen JL, Kristensen LH et al. Inhibitors of histone demethylases. Bioorg. Med. Chem. 19(12), 36253636 (2011).

152 Rose NR, McDonough MA, King ONF, Kawamura A, Schofield CJ. Inhibition of 2-oxoglutarate dependent oxygenases. Chem. Soc. Rev. 40(8), 4364-4397 (2011).

153 McGrath J, Trojer P. Targeting histone lysine methylation in cancer. Pharmacol. Ther. doi: 10.1016/j. pharmthera.2015.01.002 (2015)(Epub ahead of print).

154 Thinnes CC, England KS, Kawamura A, Chowdhury R, Schofield CJ, Hopkinson RJ. Targeting histone lysine demethylases - progress, challenges, and the future. Biochim. Biophys. Acta 1839(12), 1416-1432 (2014).

155 Hopkinson RJ, Tumber A, Yapp C et al. 5-Carboxy-8hydroxyquinoline is a broad spectrum 2-oxoglutarate oxygenase inhibitor which causes iron translocation. Chem. Sci. 4(8), 3110-3117 (2013).

156 King ONF, Li XS, Sakurai M et al. Quantitative highthroughput screening identifies 8 -hydroxyquinolines as 
cell-active histone demethylase inhibitors. PLoS ONE 5(11), e15535 (2010).

157 SGC. Epigenetics probes collection. www.thesgc.org

158 Luo X, Liu Y, Kubicek S et al. A selective inhibitor and probe of the cellular functions of Jumonji $\mathrm{C}$ domain-containing histone demethylases.. J. Am. Chem. Soc. 133(24), 9451-9456 (2011).

159 Wang L, Chang J, Varghese D et al. A small molecule modulates Jumonji histone demethylase activity and selectively inhibits cancer growth. Nat. Commun. 4, 2035 (2013)

160 Rotili D, Tomassi S, Conte M et al. Pan-histone demethylase inhibitors simultaneously targeting Jumonji $\mathrm{C}$ and lysinespecific demethylases display high anticancer activities. J. Med. Chem. 57(1), 42-55 (2014).

-161 Kruidenier L, Chung C, Cheng Z et al. A selective jumonji H3K27 demethylase inhibitor modulates the proinflammatory macrophage response. Nature 488(7411), 404-408 (2012).

162 Heinemann B, Nielsen JM, Hudlebusch HR et al. Inhibition of demethylases by GSK-J1/J4. Nature 514(7520), E1-E2 (2014).

163 Steller P. Discovery on Target. Boston, US 8-10 October 2014.

164 Papait R, Condorelli G. Epigenetics in heart failure. Ann. NY Acad. Sci. 1188, 159-164 (2010).

165 Duygu B, Poels EM, da Costa Martins PA. Genetics and epigenetics of arrhythmia and heart failure. Front. Genet. 4, 219 (2013).

166 Oka T, Komuro I. Molecular mechanisms underlying the transition of cardiac hypertrophy to heart failure. Circ. J. 72(Suppl. A), A13-A16 (2008).

167 Sano M, Minamino T, Toko H et al. p53-induced inhibition of Hif-1 causes cardiac dysfunction during pressure overload. Nature 446(7134), 444-448 (2007).

168 Handley MG, Medina RA, Nagel E, Blower PJ, Southworth R. PET imaging of cardiac hypoxia: opportunities and challenges. J. Mol. Cell Cardiol. 51(5), 640-650 (2011).

169 Kaneda R, Takada S, Yamashita Y et al. Genome-wide histone methylation profile for heart failure. Genes Cells 14(1), 69-77 (2009).

$\square_{170}$ Stein AB, Jones TA, Herron TJ et al. Loss of H3K4 methylation destabilizes gene expression patterns and physiological functions in adult murine cardiomyocytes. J. Clin. Invest. 121(7), 2641-2650 (2011).

171 Zhang QJ, Chen HZ, Wang L, Liu DP, Hill JA, Liu ZP. The histone trimethyllysine demethylase JMJD2A promotes cardiac hypertrophy in response to hypertrophic stimuli in mice. J. Clin. Invest. 121(6), 2447-2456 (2011).

- Establishes that activity of KDM4A at the promoter region of disease-specific genes may play a key role in the onset and progression of cardiac hypertrophy.

172 Movassagh M, Choy M, Knowles DA et al. Europe PMC funders group distinct epigenomic features in end-stage failing human hearts. Circulation 124(22), 2411-2422 (2013).
173 Hohl M, Wagner M, Reil J-C et al. HDAC4 controls histone methylation in response to elevated cardiac load. J. Clin. Invest. 123(3), 1359-1370 (2013).

174 Tingare A, Thienpont B, Roderick HL. Epigenetics in the heart: the role of histone modifications in cardiac remodelling. Biochem. Soc. Trans. 41(3), 789-796 (2013).

175 Papait R, Cattaneo P, Kunderfranco P et al. Genomewide analysis of histone marks identifying an epigenetic signature of promoters and enhancers underlying cardiac hypertrophy. Proc. Natl Acad. Sci. USA 110(50), 2016420169 (2013).

- Analyzes the role of changes to epigenetic marks at the promoter and enhancer regions of disease-related genes in both establishing and driving maladaptive phenotypic changes in cardiac hypertrophy.

176 Sheikh F, Raskin A, Chu P-H et al. An FHL1-containing complex within the cardiomyocyte sarcomere mediates hypertrophic biomechanical stress responses in mice. $J$. Clin. Invest. 118(12), 3870-3880 (2008).

177 Björnheden T, Levin M, Evaldsson M, Wiklund O. Evidence of hypoxic areas within the arterial wall in vivo. Arterioscler. Thromb. Vasc. Biol. 19(4), 870-876 (1999).

178 Vink A, Schoneveld AH, Lamers D et al. HIF-1 alpha expression is associated with an atheromatous inflammatory plaque phenotype and upregulated in activated macrophages. Atherosclerosis 195(2), e69-e75 (2007).

179 Zhang W-J, Wei H, Frei B. The iron chelator, desferrioxamine, reduces inflammation and atherosclerotic lesion development in experimental mice. Exp. Biol. Med. (Maywood) 235(5), 633-641 (2010).

180 De Santa F, Totaro MG, Prosperini E, Notarbartolo S, Testa G, Natoli G. The histone H3 lysine-27 demethylase Jmjd3 links inflammation to inhibition of polycomb-mediated gene silencing. Cell 130(6), 1083-1094 (2007).

181 De Santa F, Narang V, Yap ZH et al. Jmjd3 contributes to the control of gene expression in LPS-activated macrophages. EMBO J. 28(21), 3341-3352 (2009).

182 Yan Q, Sun L, Zhu Z, Wang L, Li S, Ye RD. Jmjd3-mediated epigenetic regulation of inflammatory cytokine gene expression in serum amyloid A-stimulated macrophages. Cell. Signal. 26(9), 1783-1791 (2014).

183 King VL, Thompson J, Tannock LR. Serum amyloid A in atherosclerosis. Curr. Opin. Lipidol. 22(4), 302-307 (2011).

184 Lippi G, Franchini M, Targher G. Arterial thrombus formation in cardiovascular disease. Nat. Rev. Cardiol. 8(9), 502-512 (2011).

185 Iwamori N, Zhao M, Meistrich ML, Matzuk MM. The testis-enriched histone demethylase, KDM4D, regulates methylation of histone $\mathrm{H} 3$ lysine 9 during spermatogenesis in the mouse but is dispensable for fertility. Biol. Reprod. 84(6), 1225-1234 (2011).

186 Shpargel KB, Starmer J, Yee D, Pohlers M, Magnuson T. KDM6 demethylase independent loss of histone $\mathrm{H} 3$ lysine 27 trimethylation during early embryonic development. PLoS Genet. 10(8), e1004507 (2014).

187 Miller SA, Mohn SE, Weinmann AS. Jmjd3 and UTX play a demethylase-independent role in chromatin remodeling to 
regulate T-box family member-dependent gene expression. Mol. Cell 40(4), 594-605 (2010).

188 Khoury-Haddad H, Guttmann-Raviv N, Ipenberg I, Huggins D, Jeyasekharan AD, Ayoub N. PARP1-dependent recruitment of KDM4D histone demethylase to DNA damage sites promotes double-strand break repair. Proc. Natl Acad. Sci. USA 111(7), E728-E737 (2014).
189 Watson JA, Watson CJ, McCrohan A-M et al. Generation of an epigenetic signature by chronic hypoxia in prostate cells. Hum. Mol. Genet. 18(19), 3594-3604 (2009).

190 Shahrzad S, Bertrand K, Minhas K, Coomber BL. Induction of DNA hypomethylation by tumor hypoxia. Epigenetics 2(2), 119-125. 